\title{
Health Challenges and Comorbidities Experienced by People Living with Human Immunodeficiency Virus in Developed Nations: A Systematic Review
}

\author{
Lisa Johnson ${ }^{1}$, Carol Ann Flavell ${ }^{2}$ \\ ${ }^{1,2}$ College of Healthcare Sciences, James Cook University, Australia \\ Email: lisa.johnson2@my.jcu.edu.au, carol.flavell@jcu.edu.au
}

\begin{abstract}
Introduction: Studies have reported the prevalence, incidence and risk of health challenges and comorbidities experienced by people living with HIV (PLHIV) in developed countries. Yet, no systematic review to appraise and summate these studies exists.

Methods: Electronic database searches included studies conducted in developed countries which reported health challenges and comorbidities in PLHIV compared to a HIV negative population. Critical appraisal was conducted using the Appraisal Tool for Cross Sectional Studies (AXIS).

Results: Eligible studies $(n=51)$ were of moderate to high methodological quality (range: 7-19/20). PLHIV had increased rates or risk of ischaemic stroke, myocardial infarction, reduced bone mineral density, lung and anal cancer, chronic obstructive pulmonary disease, lung infections, and peripheral lipodystrophy.

Conclusions: In developed countries several health challenges and comorbidities remain of greater concern in PLHIV compared to HIV negative individuals. Evidence for other comorbidities remains limited or inconclusive, and requires further research.
\end{abstract}

Keywords: Adult, AIDS, Developed Countries, HIV, Health, Review.

\section{Introduction}

In most developed countries, Human Immunodeficiency Virus (HIV) has become a chronic, nonterminal condition, due in part to early diagnosis and the introduction of antiretroviral therapy (ART) [1]. The resulting increased life expectancy of PLHIV now approaches that of the HIV uninfected (HIV-ve) population $[2,3,4]$.

Nevertheless, despite increased life expectancy, PLHIV can experience a variety of physical and psychological health challenges compared to HIVve individuals $[5,6]$. These findings have been related to aging with HIV in line with increased life expectancy [5], but also the direct effect of HIV infection, or the sequelae of ART [2].

Previous research has reported the prevalence, incidence, and risk of health challenges and comorbidities in PLHIV. A synopsis of which, includes decreased bone mineral density, increased rates of neurocognitive impairments, and respiratory symptoms [7,8], and high rates of dyslipidaemia and increased muscle fat content, resulting in weakness, falls, decline in physical activity [9], psychological and social function, which can manifest as 'frailty' [10]. Therefore, the potential for these comorbidities and health challenges to increase disability and thus reduce quality of life in this population is of concern.
Yet no study has systematically reviewed the evidence from developed countries on prevalence, incidence or risk rates for health challenges and comorbidities in PLHIV compared to the HIV-ve population.

No critically appraised, summative, and comparative evidence exists to show if any health challenges and comorbidities are experienced by, or pose a greater risk in PLHIV. Thus, health professionals who manage these HIV related challenges and comorbidities, and their sequalae remain uninformed of the greater healthcare needs specific to PLHIV. The purpose of this systematic review was to critically appraise published literature which reported health challenges and co-morbidities experienced by PLHIV compared to matched HIV-ve individuals in developed countries.

\section{Methods}

This review was guided by the Preferred Reporting Items for Systematic Reviews and Meta-analyses (PRISMA) framework [11], and was registered with the International Prospective Register of Systematic reviews (CRD42020147864).

\section{Eligibility Criteria}

Studies were published in English, from peer-reviewed journals, were conducted in developed countries as 
defined previously [12], reported prevalence, incidence, or risk of any health challenge or co-morbidities in a HIV positive (HIV+ve) target population ( $\geq 18$ years) with or without exposure to ART, and included a comparison HIV-ve population, or profile statistics from an existing epidemiological data set. Studies which included pregnant women, were reviews, meta-analyses, opinion pieces, or conference proceedings were excluded.

\section{Search Strategy and Study Selection}

Between $1^{\text {st }}$ June and $31^{\text {st }}$ July 2019, Medline, Emcare, CINHAL and Scopus were searched using a pre-determined search string (Table 1).

Identified articles were imported to Endnote ${ }^{T M}$ (X8.2). Duplicates were deleted and titles screened for relevance (LJ). Suitable abstracts were then screened and full text articles selected (LJ \& CAF). At each stage both reviewers were blinded to each other's decision. Articles for quality appraisal were approved following reviewer discussion and consensus.

\section{Quality Assessment of Included Studies}

Articles were critically appraised using the Appraisal Tool for Cross Sectional Studies (AXIS) [13]. To maximise reliability between reviewers, the interpretation of each AXIS guideline was discussed prior to its application. Reviewers independently appraised articles before discussion to reach consensus on scores. Study quality was categorised as low ( $\leq 4$ axis criteria met), low to moderate (5-10), moderate to high (11-15), or high (>15) as described previously [14].

Table 1: Search Strings

\begin{tabular}{llll}
\hline HIV String & ART String & Health condition and/or co-morbidity string \\
\hline HIV coinfection & HAART & Disease & Osteopenia \\
HIV coinfections & Highly active & Cardiovascular disease & Multiple sclerosis \\
HIV infection & antiretroviral therapy & Cardiovascular diseases & Metabolic syndrome \\
HTLV iii infections & ART & Heart & Carcinoma \\
HTLV iii lav infections & Antiretroviral therapy & Musculoskeletal disease & Insulin resistance \\
HTLV-iii infection & Anti-HIV agents & Musculoskeletal diseases & Cancer \\
HTLV-iii infections & & Orthopaedic disorder & Diabetes mellitus \\
HTLV-iii-lav-infection & & Respiratory tract disease & Type 2 diabetes \\
HTLV-iii-lav infections HIV & Respiratory tract diseases & Depression \\
HTLV-iii & Anaemia & Anxiety \\
Human immunodeficiency virus & & Myocardial infarction & Psychosocial disorders \\
Human immunodeficiency viruses & & Ml & Loneliness \\
Human t cell leukemia virus & & Tuberculosis & Neurocognitive \\
type iii & Physical impairment & disorders \\
Human t cell lymphotropic virus & & Impairment & Neuro psycho-social \\
type iii & Impairments & impairment \\
Human t-cell lymphotropic virus & Deficit & HIV associated \\
type iii & Deficits & dementia \\
Human t-lymphotropic virus & Gait deficit & Visual deficit \\
type iii & Locomotor impairment & Memory deficit \\
Lav-HTL-iii & Balance & Encephalitis \\
Lymphadenopathy associated virus & Abnormal gait & Frailty \\
Lymphadenopathy-associated virus & Co morbidities & Drug sensitivity \\
Lymphadenopathy-associated & Comorbidity & Adverse drug reaction \\
viruses & Dementia & Health challenge \\
Virus & Osteoporosis & Multi-morbidity \\
Human immunodeficiency & & Neuropathy \\
Viruses & & Lipodystrophy \\
Lymphadenopathy-associated & & Neurological \\
HIV seropositivity & & \\
Lymphadenopathy associated & & & \\
retrovirus & & & \\
\hline ART:Antisetrovirat Therap y; & & \\
\hline
\end{tabular}

ART: Antiretroviral Therap y; HTLV: Human T lymphotrophic Virus; HAART: Highly Active Antiretroviral Therapy; MI: Myocardial Infarction;

HIV: Human Immunodeficiency Virus 


\section{Data Extraction}

AXIS scores and key article information was extracted and tabulated to allow comparison and synthesis of research findings, risk of bias, and quality rating.

\section{Results}

Searches yielded 6,814 studies. The database search and selection process are shown in Figure 1 . The fiftyone appraised articles included cohort studies $(n=23)$, cross-sectional studies $(n=23)$, case control studies $(n=4)$, and a retrospective medical chart review $(n=1)$.

Reported health challenges and co-morbidities were categorised into 14 groups (Table 2). The reporting of prevalence, incidence, or risk for cardiovascular related diseases predominated. Six of the groups were represented by only one article. Overall quality of studies was moderate to high (range 7-19). Eight articles were high quality (range 16-19), 41 moderate to high quality (range 10-15), and two low to moderate quality (range 7-9) (Table 3).

\section{HIV Related Cardio Vascular (CV) Disease}

Out of 15 articles, two rated high quality $[15,16]$, and 13 moderate to high (Table 2). Prevalence of a CV related disease was reported by five articles [17-21], incidence by six $[15,22-26]$, and risk by nine [15,16,23-29]. Six

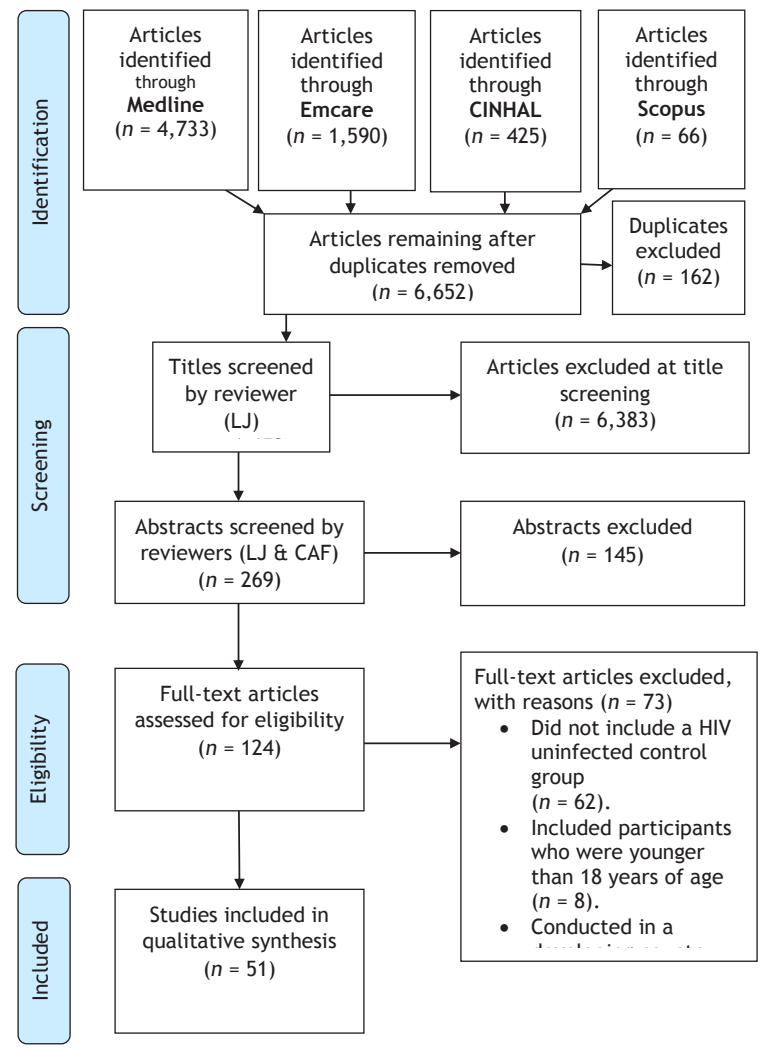

Figure 1: PRISMA Flow Chart of Selected Studies articles reported a combination of either prevalence, incidence, or risk [15,16,23-26]. Four articles reported the prevalence of hypertension [17-20], three of which reported prevalence to be no greater in PLHIV compared to HIV-ve controls $[17,18,20]$. Peripheral vascular disease (PAD) was the focus of only one article which identified a significantly higher cumulative incidence of PAD, and post-PAD event mortality in PLHIV [15].

Four studies reported on coronary artery disease $[21,24,26,28]$, of which three reported the incidence and/or risk of acute coronary events $[24,26,28]$. The other reported prevalence of coronary atherosclerosis using the Coronary Artery Disease-Reporting and Data System, and found a significantly increased prevalence of coronary atherosclerosis in PLHIV $(2.21 \pm 1.4$ vs. 1.69 $\pm 1.5 ; p=0.031$ ) [21].

Two of the studies on acute coronary events detailed higher rates of acute myocardial infarction (AMI) in PLHIV $[24,26]$. Greater incidence, with increased odds ratio for $\mathrm{AMI}$ was associated with the antiretrovirals abacavir, efavirenz, lopinavir, and ritonavir, indicating greater risk for AMI in PLHIV, associated with exposure to certain ARTs [24]. Similarly, increased relative risk for AMI was found in HIV+ve women [26].

In contrast, De Socio et al. [28] used the Framingham Risk Score (FRS) to show that average 10-year risk for acute CV disease was not significantly different for PLHIV. However, risk of death from CV disease was greater in PLHIV. The FRS was used by Bergersen et al. [27] showing risk of CV disease ( $>20 \%$ ) was more than double in PLHIV on HAART. A later study also reported increased risk in PLHIV, but this was not significant compared with HIV-ve controls $(p=0.24)$ [29]. A third study showed significantly increased incidence of CV disease identified from ICD-9 codes in younger PLHIV ( $M<34 y r s ; F<44 y r s)$ [23].

Greater Incidence or risk of ischaemic stroke (IS) in PLHIV was reported by three articles [16,22,25]. HIV was an independent predictor of IS, with incidence particularly higher in young and female PLHIV, independent of common risk factors [22]. Similarly, veterans living with HIV demonstrated a higher IS incidence (IR 1.25 [1.091.43]; $p=0.01$ ), and risk (HR 1.17 [1.01-1.36]; $p=0.04$ ), compared to their HIV-ve counterparts [25]. The third article reported increased incidence and risk in HIV+ve women, highlighting a risk almost twice that of HIV-ve women. Interestingly, this risk was lowered by long term ART exposure (HR 0.86 per year, $95 \% \mathrm{Cl}$ : 0.76-0.96) [16].

HIV Related Changes in Bone Mineral Density (BMD) All articles in this category found significantly reduced $B M D$, altered bone metabolism, or higher rates of 


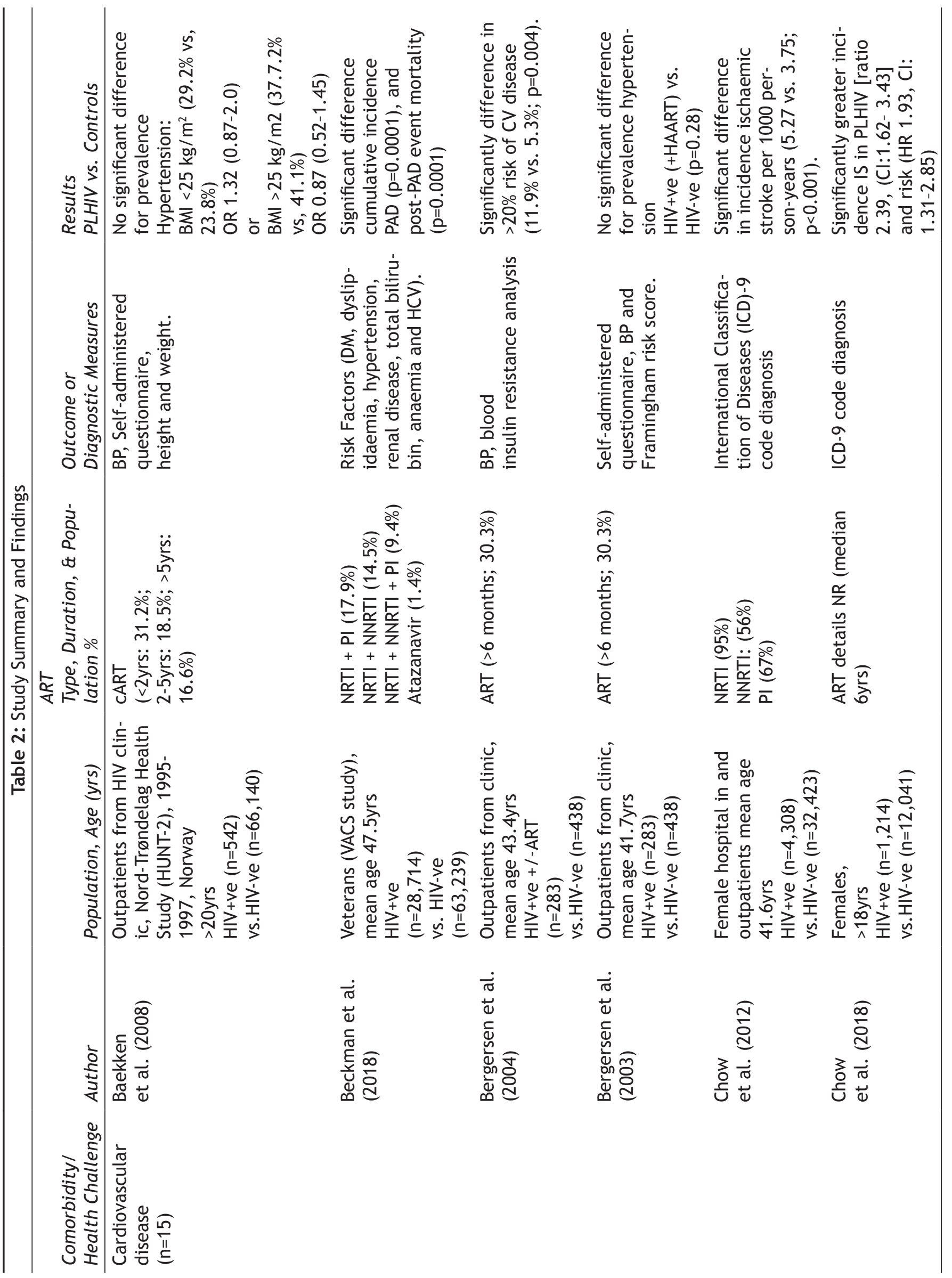




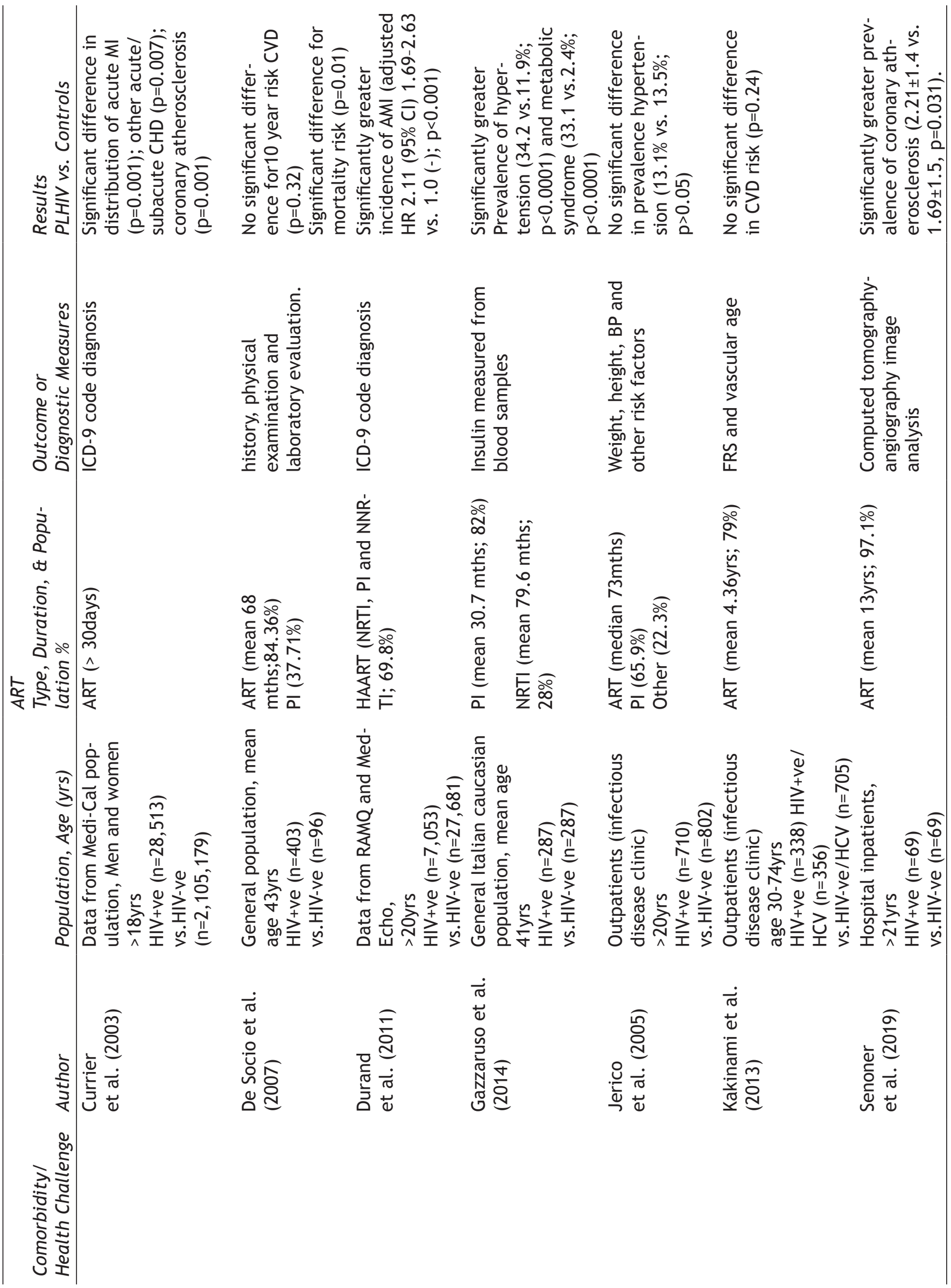




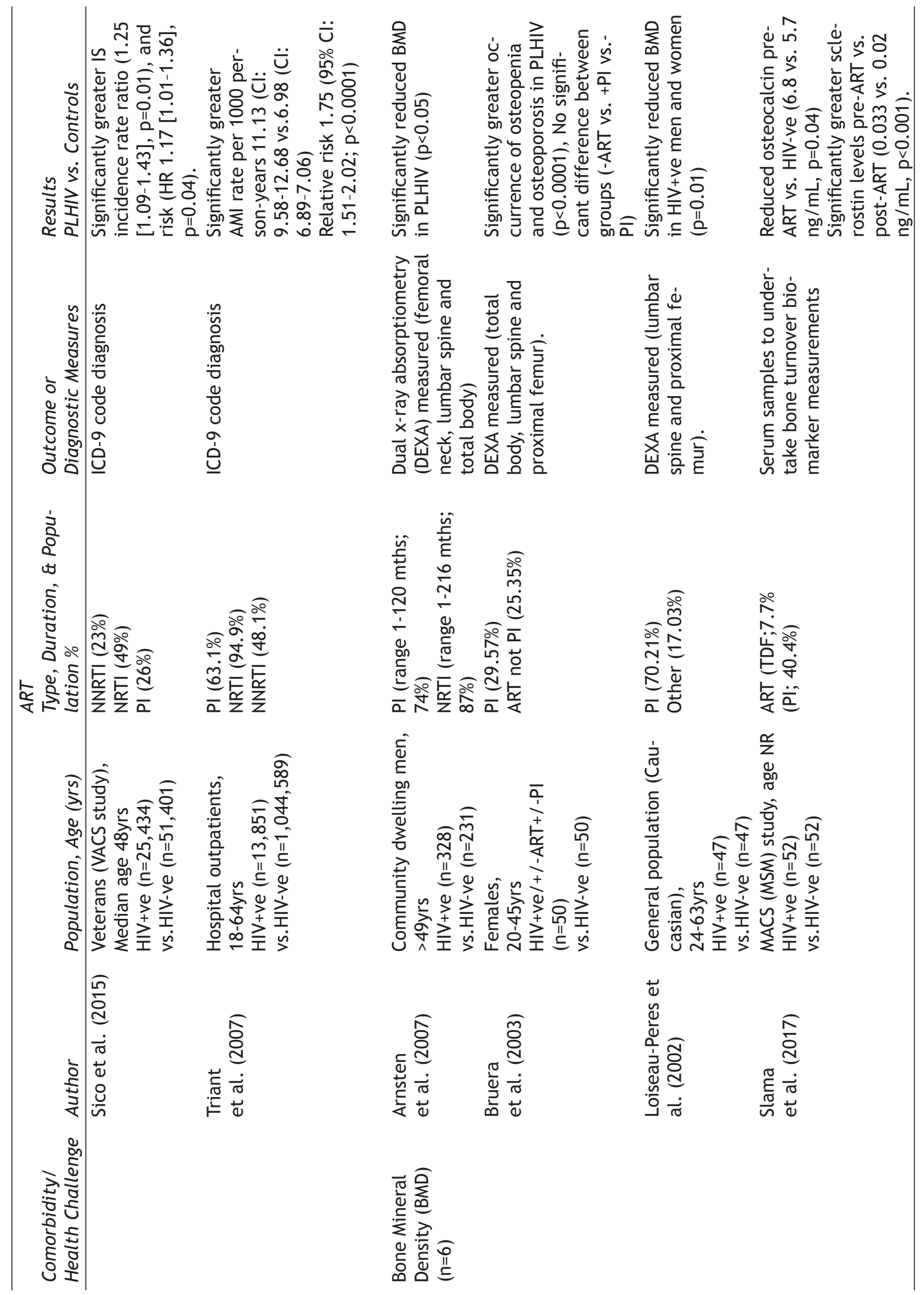




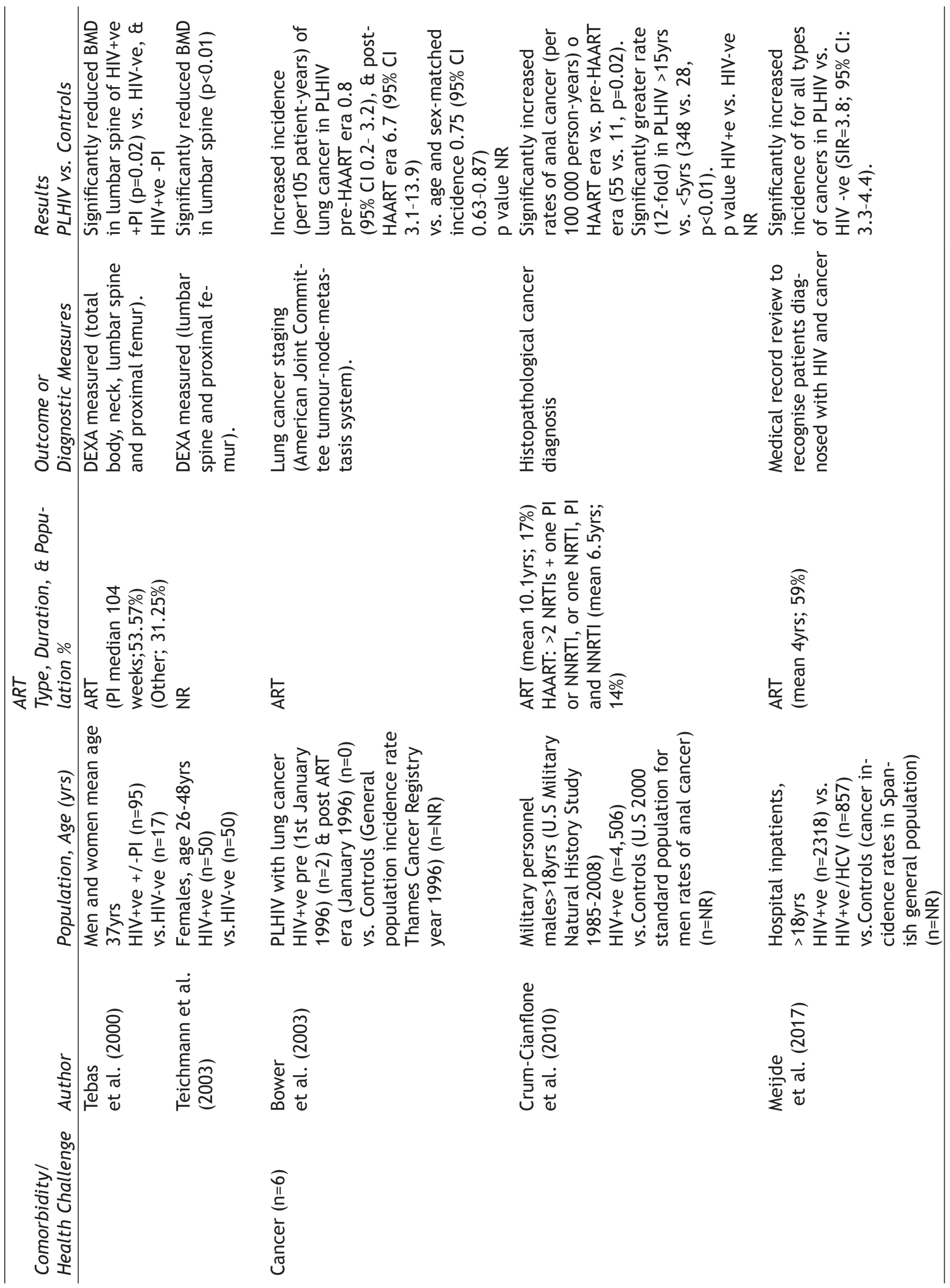




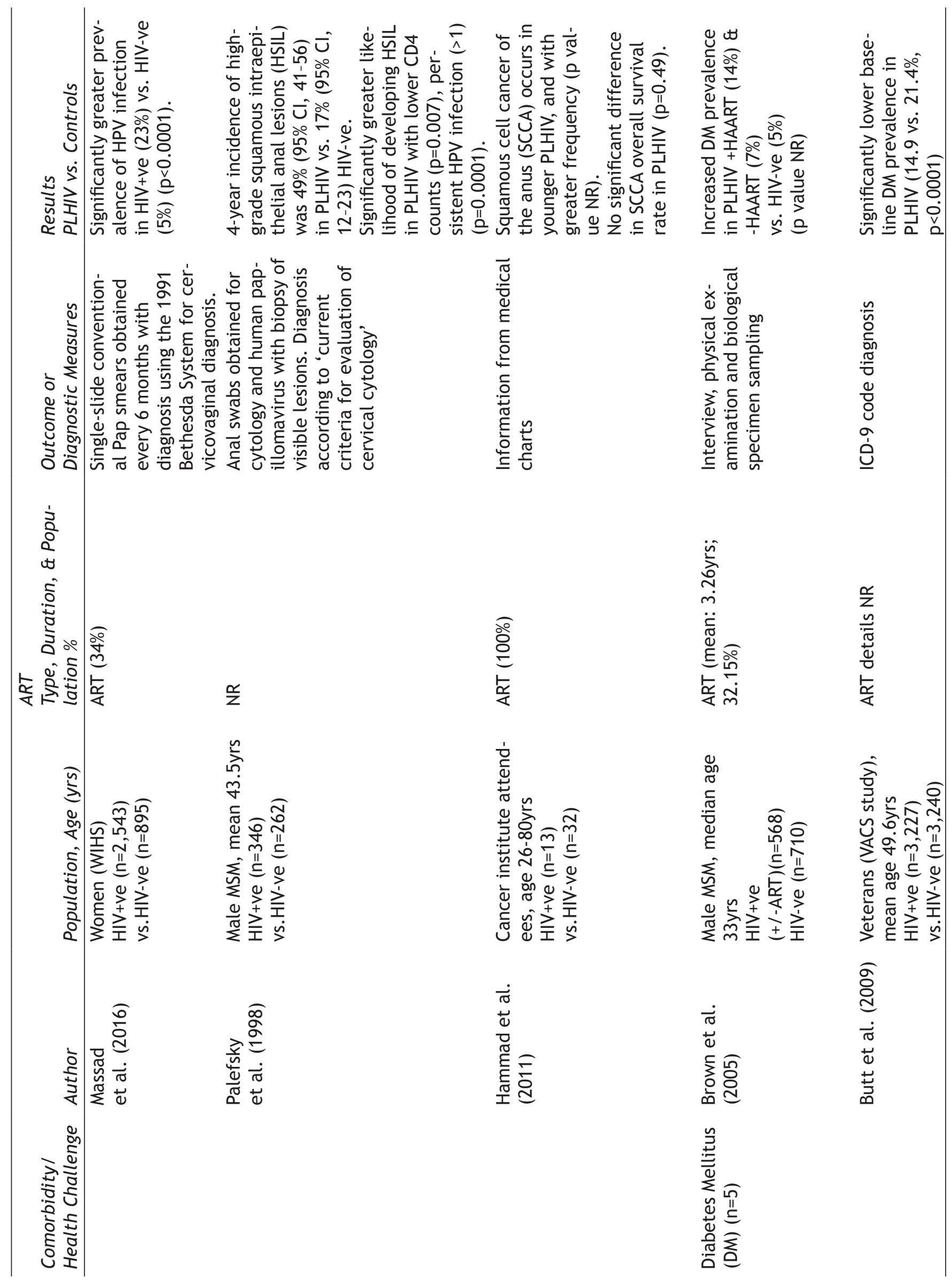




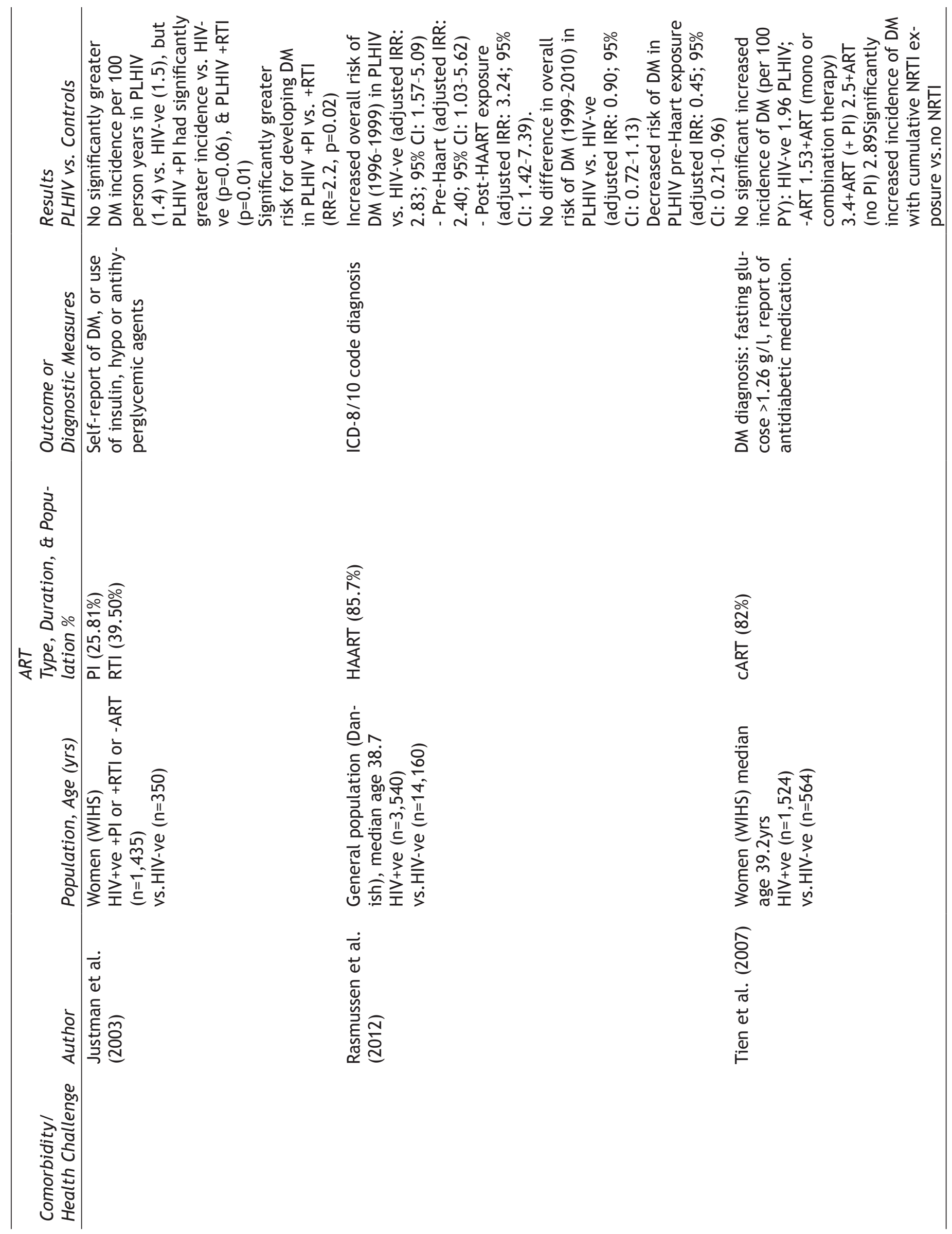




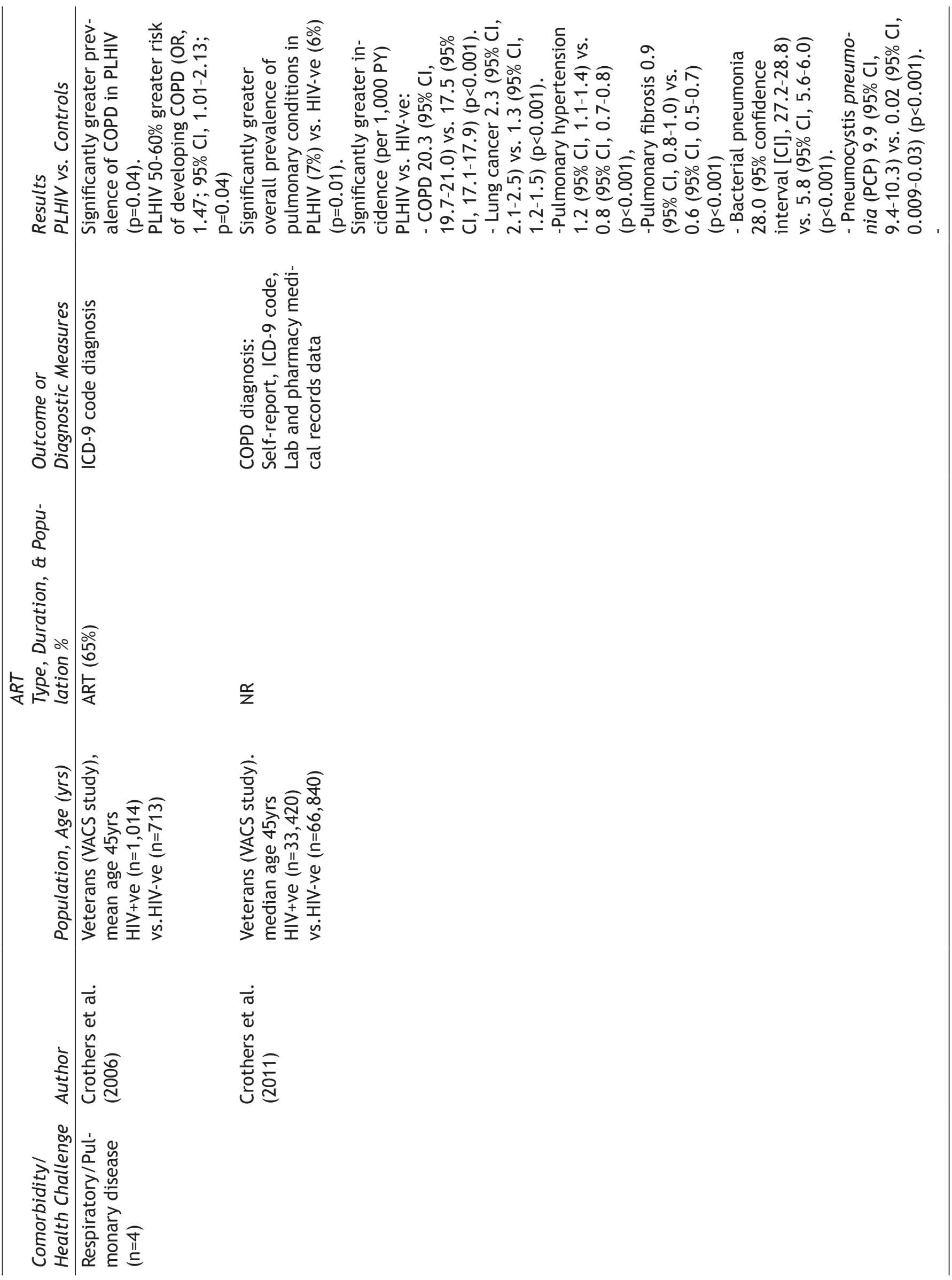




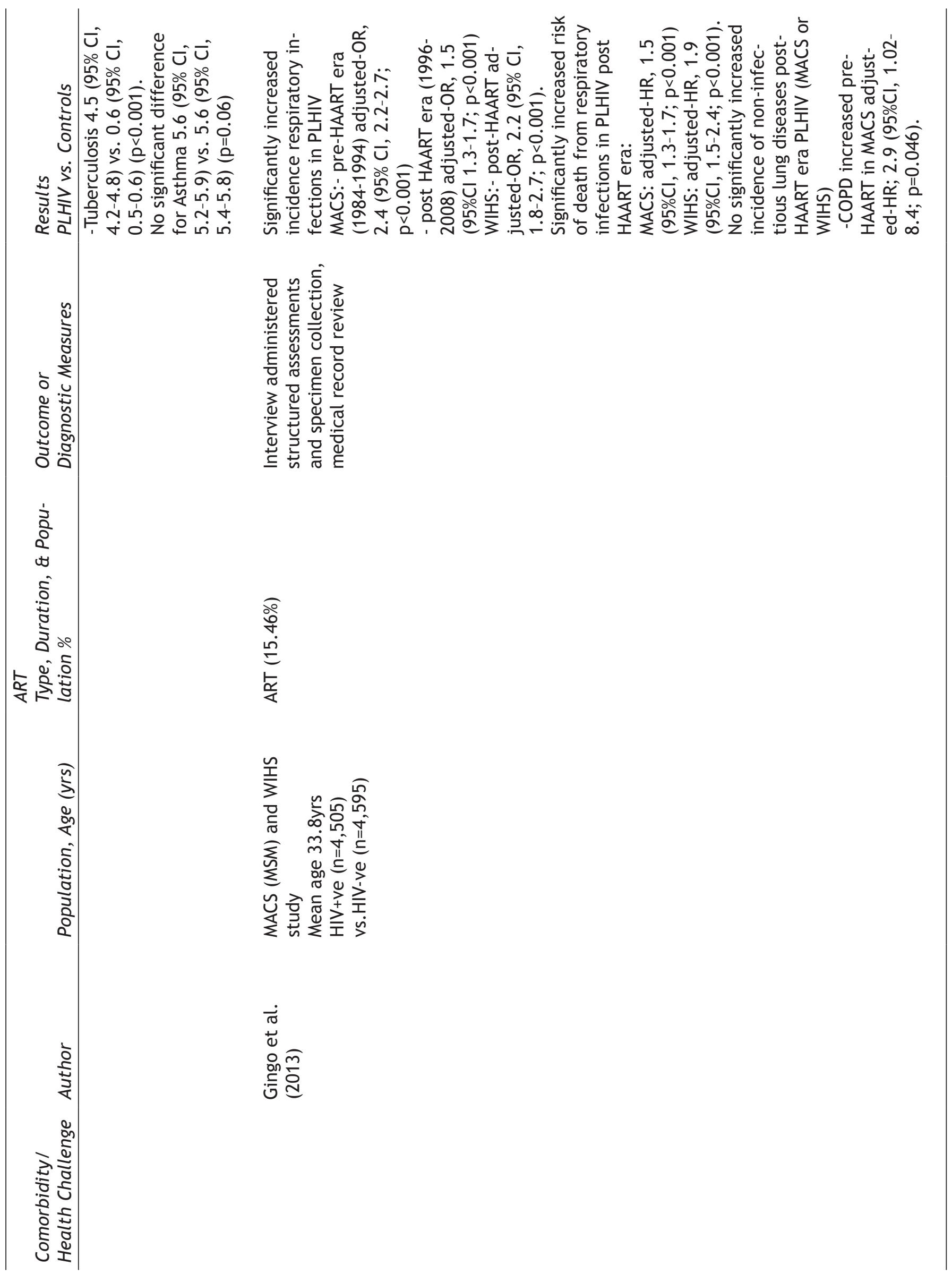




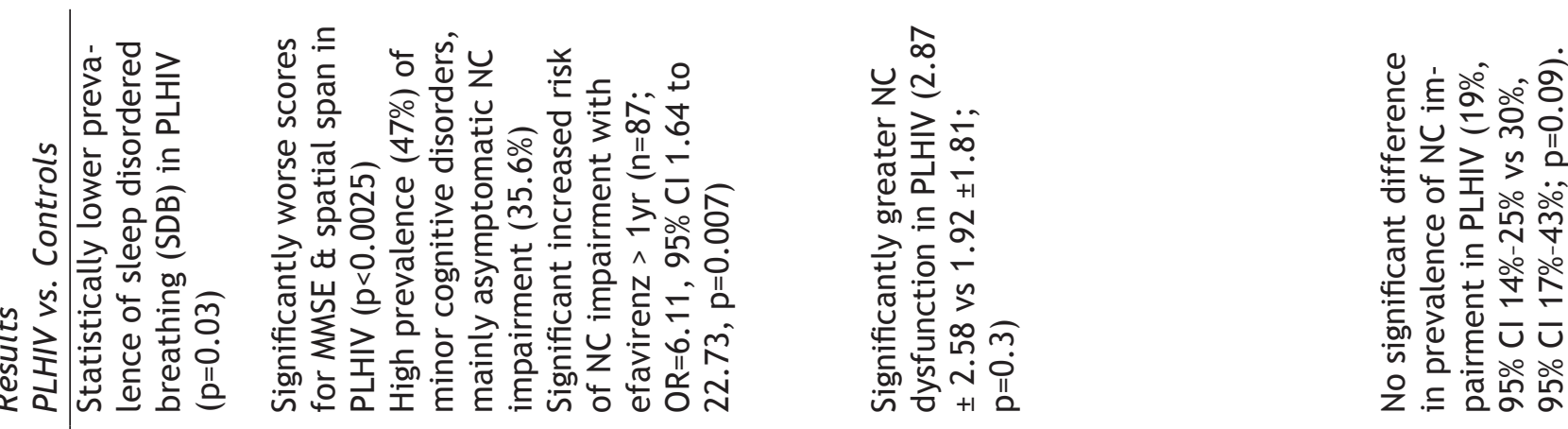

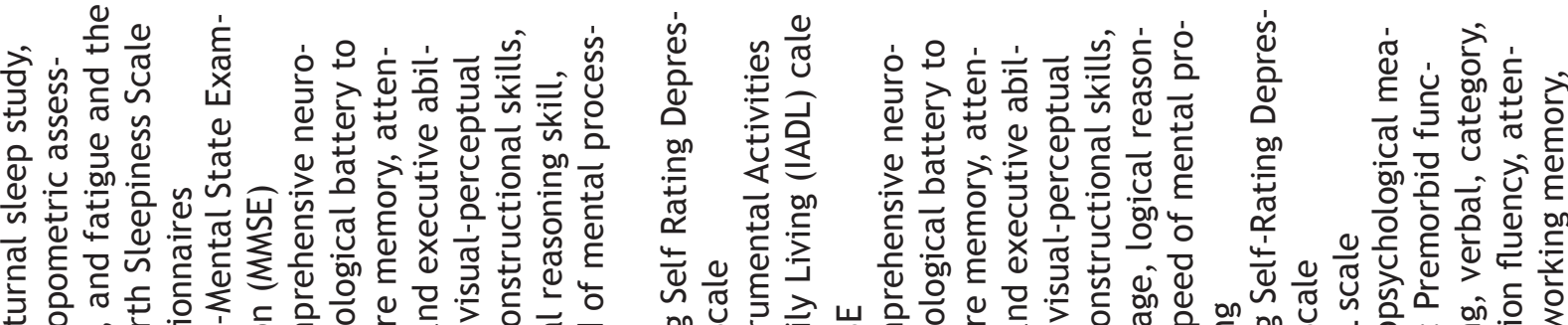
है

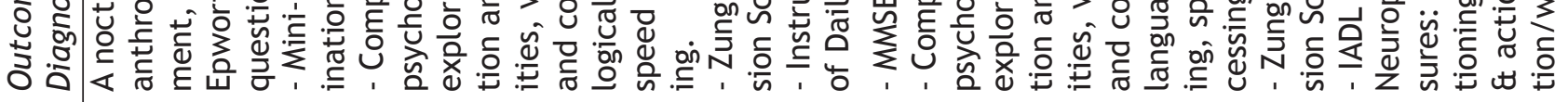

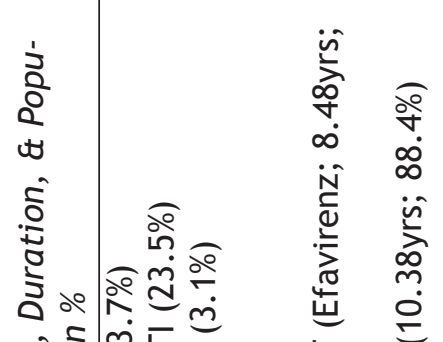

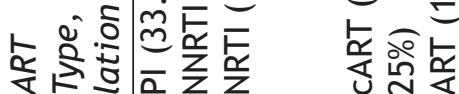

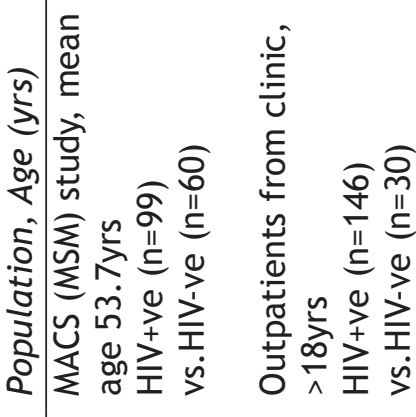

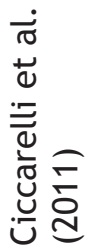

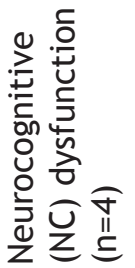

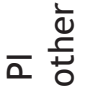

نे

둥

宛

든

눙 ㅇํㅇ

宅 ㅇํำ

:

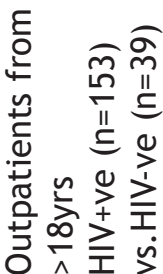

$\dot{\sigma}$

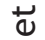

$\overline{\overline{0}}$

芯苍
苑

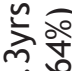

$\bar{c}$

등 ํํำ

हᄐ 듬

哭

它

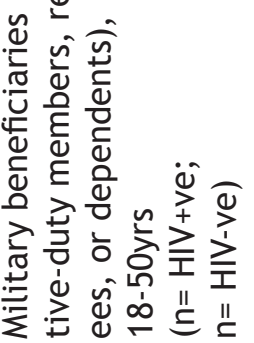

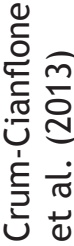




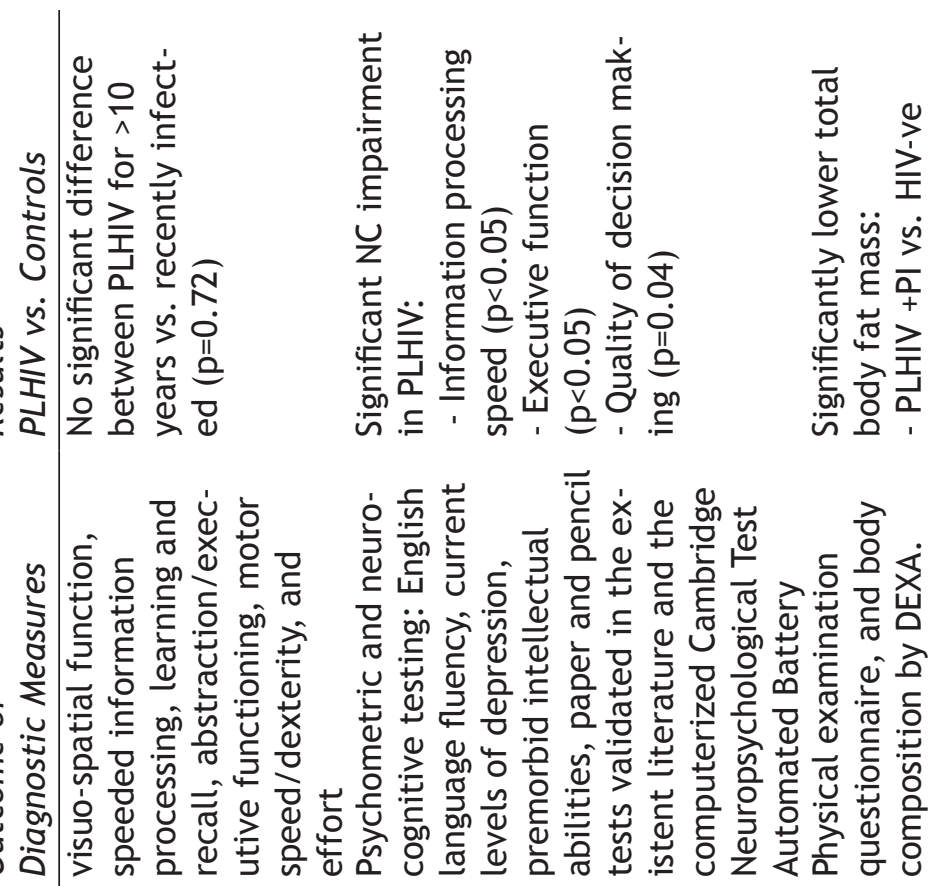

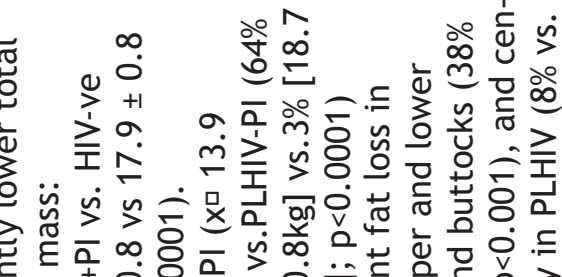

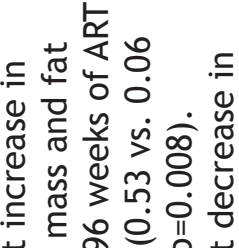

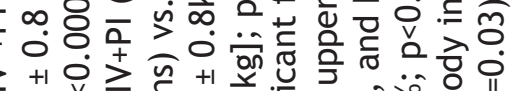

는은 은

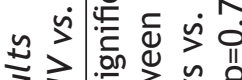

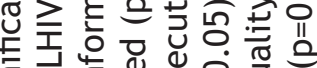

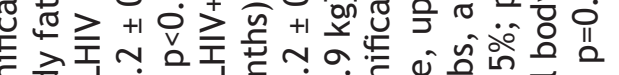
希吉

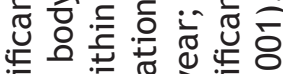

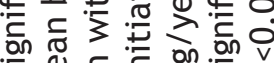

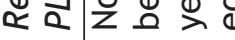
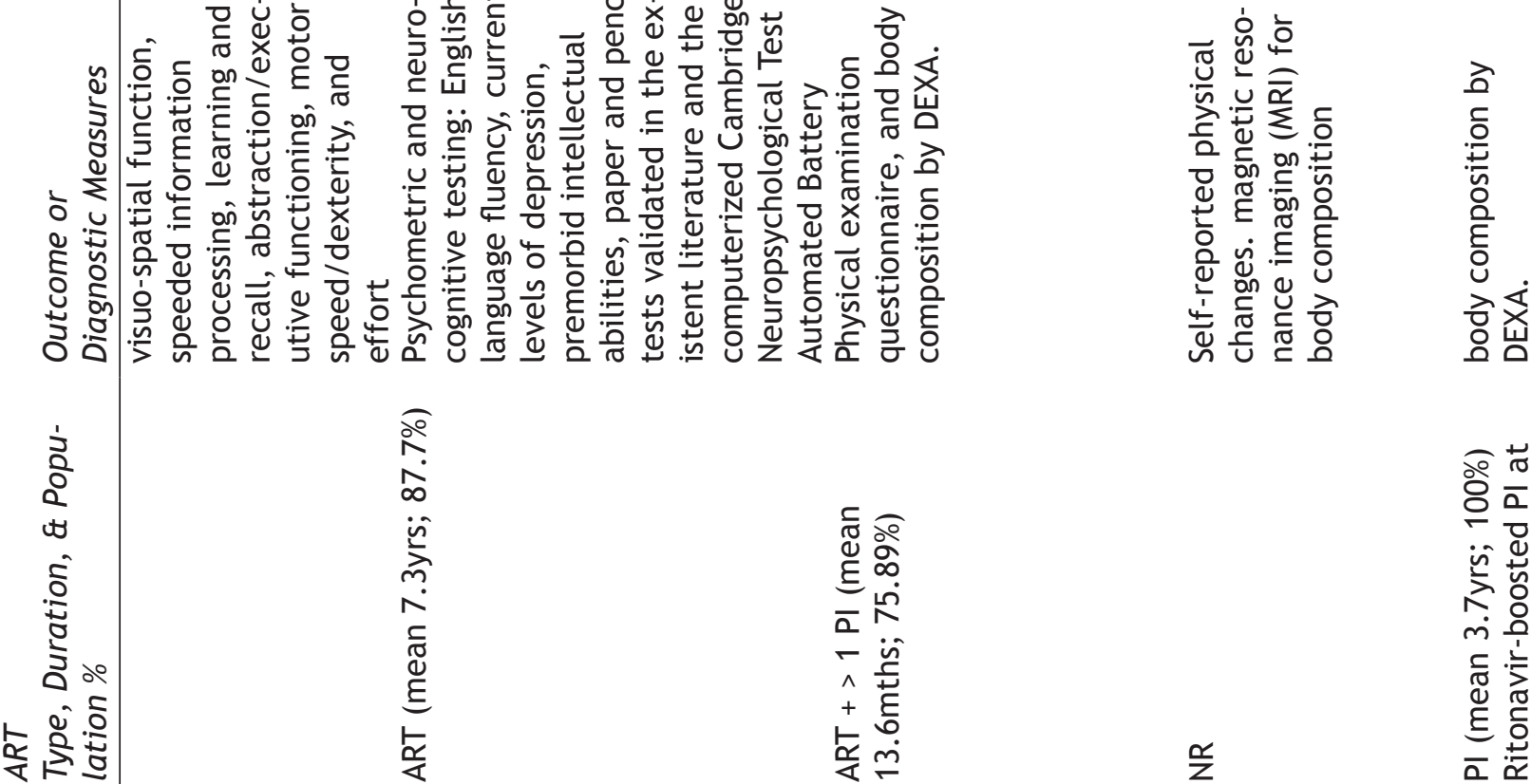

ㅇํㅇ $\frac{\pi}{\alpha}$

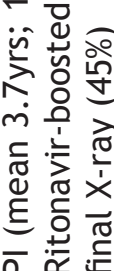

告

$\stackrel{\Upsilon}{z}$
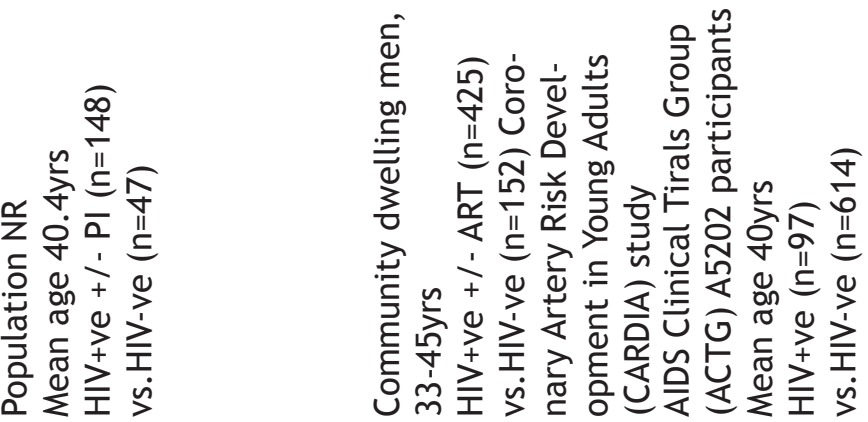

$\widehat{\infty}$
$\stackrel{0}{\Xi}$
$\dot{0}$
$\stackrel{0}{0}$
$\stackrel{0}{0}$
$\stackrel{0}{0}$
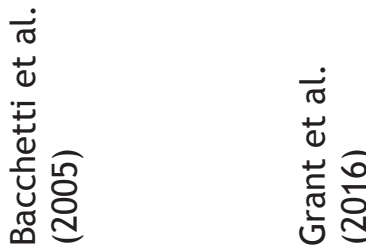

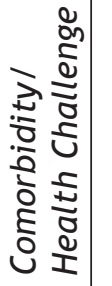

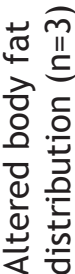




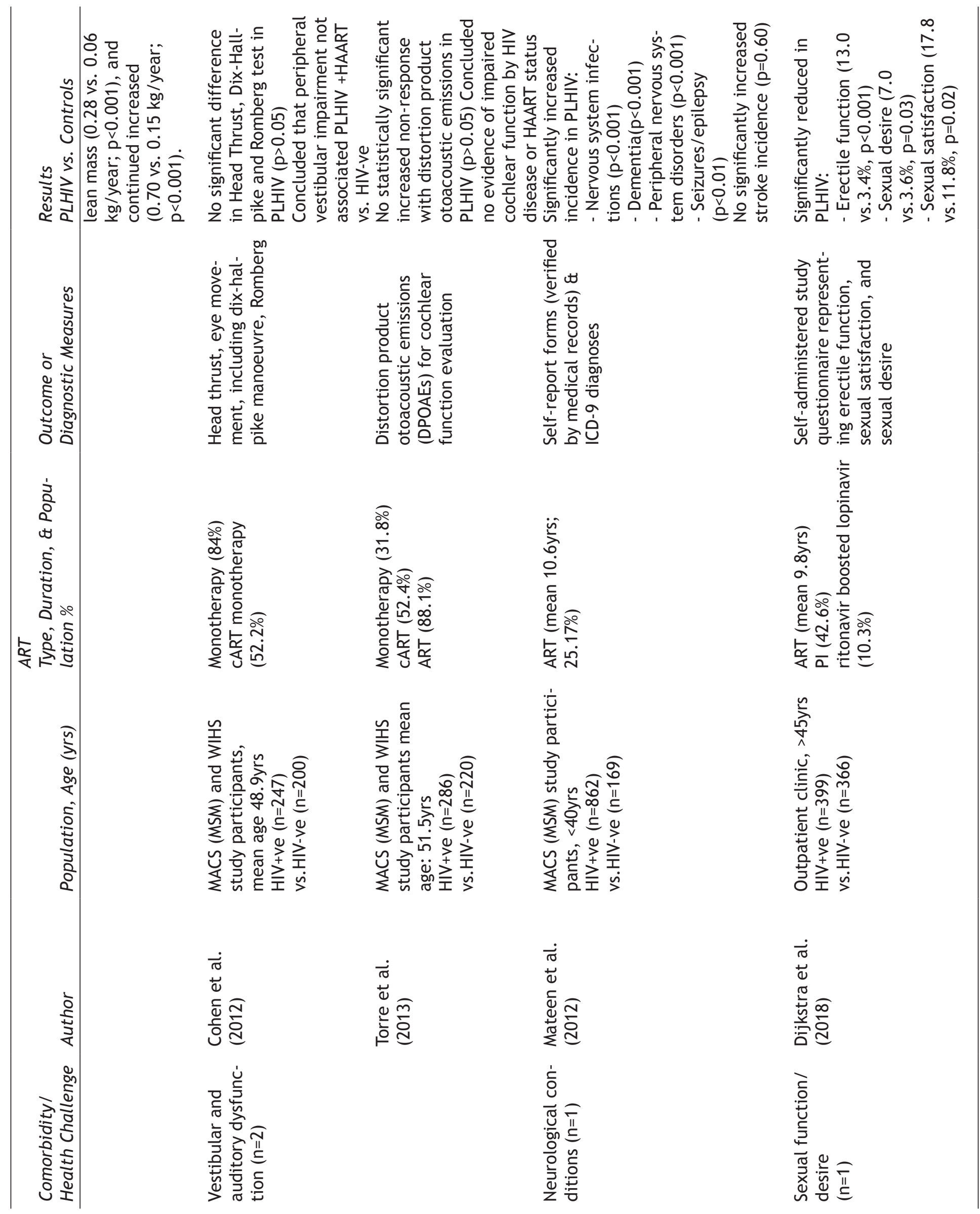




\begin{tabular}{|c|c|c|c|c|}
\hline 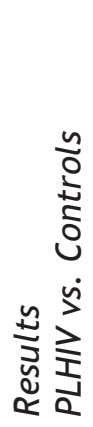 & 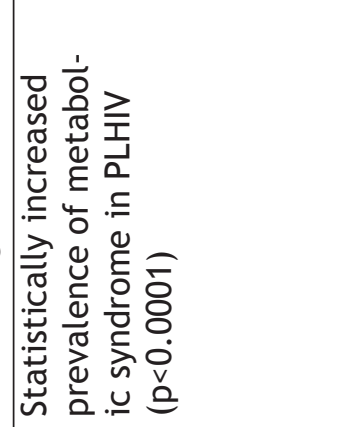 & 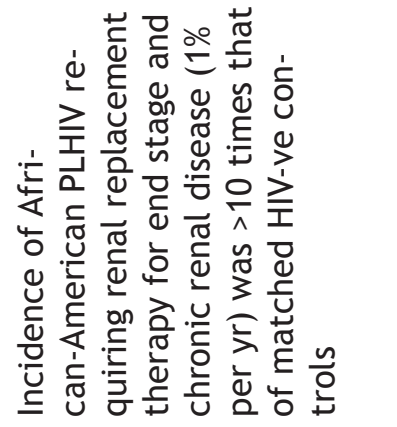 & 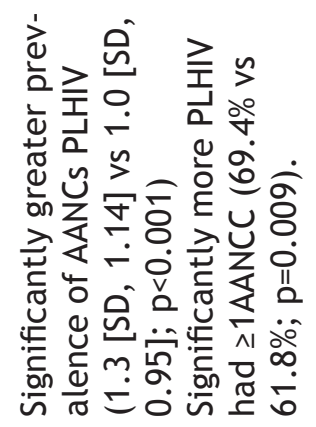 & 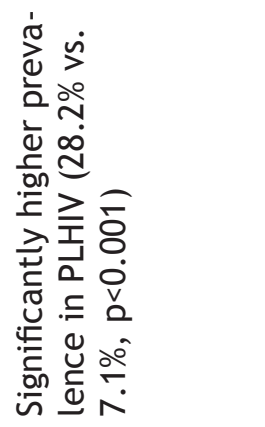 \\
\hline 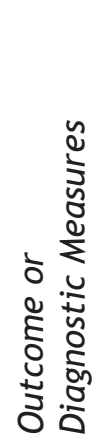 & 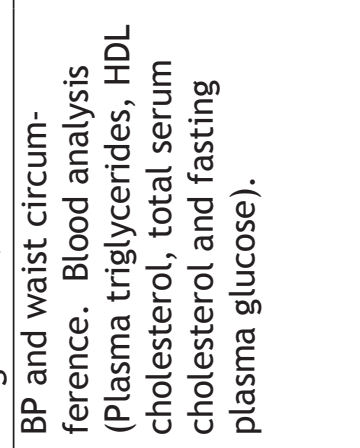 & 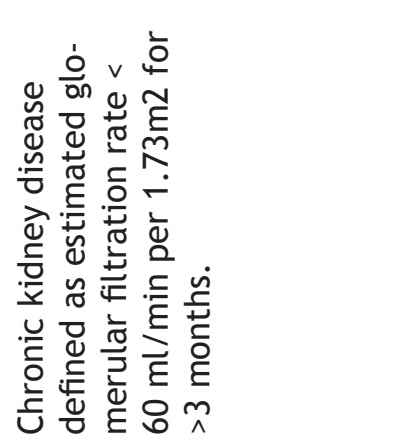 & 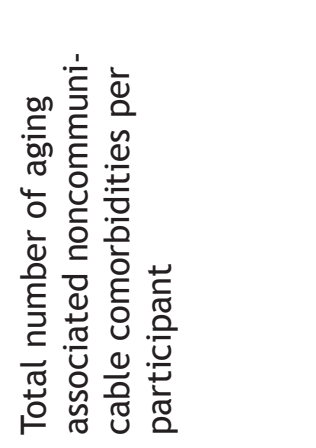 & 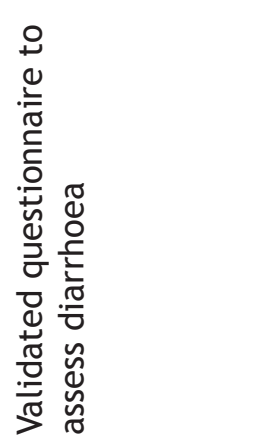 \\
\hline 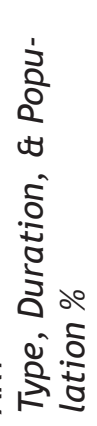 & $\frac{\underline{z}}{\underline{z}}$ & 号 & 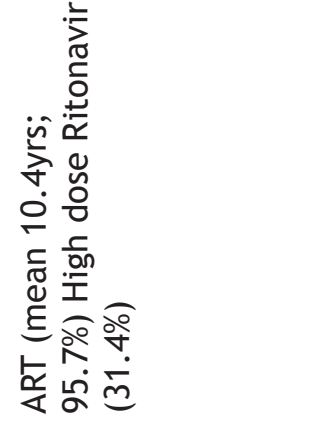 & 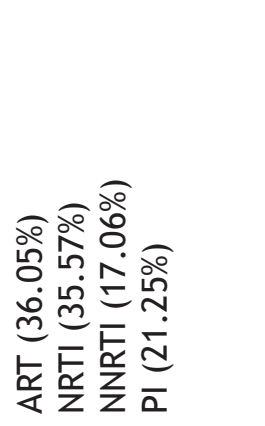 \\
\hline 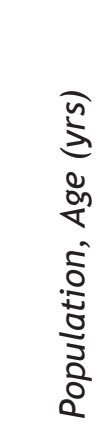 & 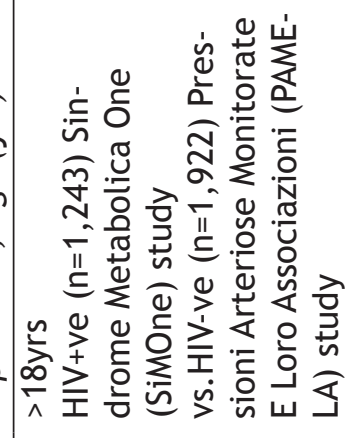 & 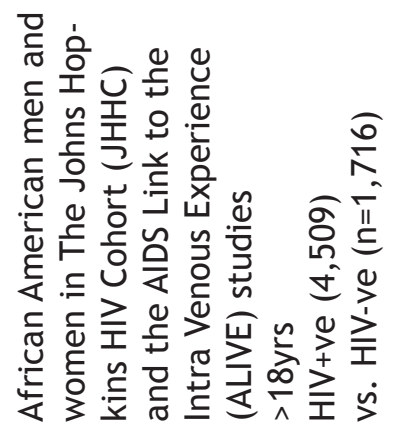 & 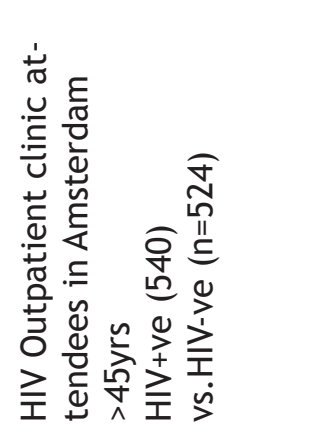 & 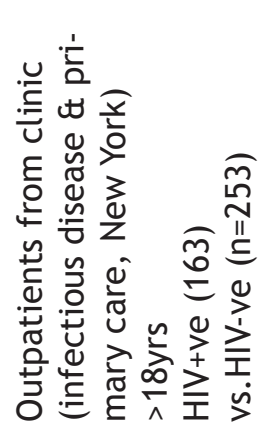 \\
\hline & 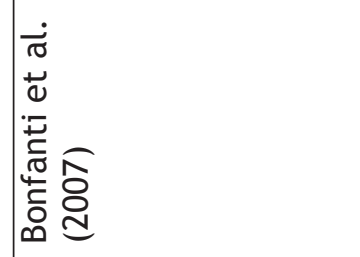 & $\begin{array}{l}\dot{\sigma} \\
\stackrel{0}{0} \\
\tilde{J} \widetilde{\delta} \\
\stackrel{\Xi}{\Xi}\end{array}$ & 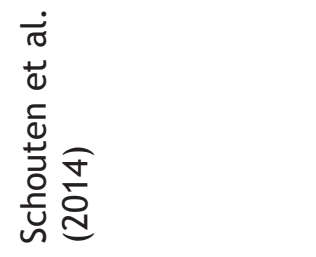 & 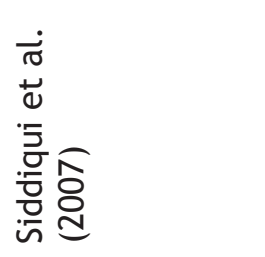 \\
\hline 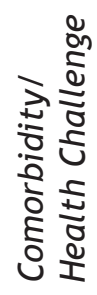 & 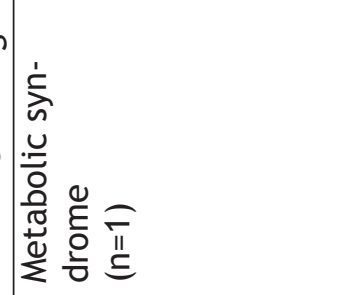 & 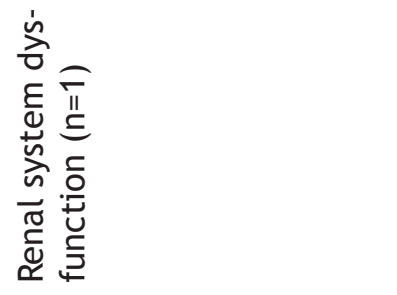 & 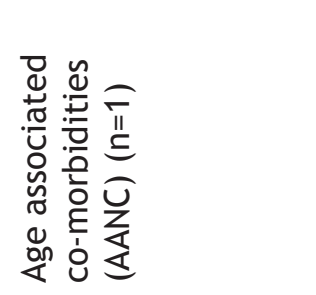 & 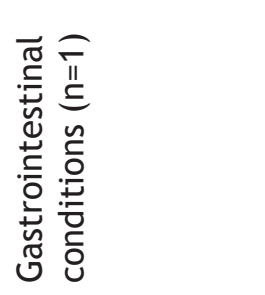 \\
\hline
\end{tabular}


Table 3: Articles according to reported comorbidity or health challenge and AXIS quality appraisal score

\begin{tabular}{|c|c|c|c|}
\hline $\begin{array}{l}\text { Comorbidity/ } \\
\text { Health Challenge }\end{array}$ & Author & $\begin{array}{l}\text { AXIS } \\
\text { Criteria Met }\end{array}$ & Quality Rating \\
\hline \multirow{15}{*}{$\begin{array}{l}\text { Cardiovascular disease } \\
(n=15)\end{array}$} & Baekken et al. (2008) & $14 / 20$ & Moderate to High \\
\hline & Beckman et al. (2018) & $16 / 20$ & High \\
\hline & Bergersen et al. (2004) & $12 / 20$ & Moderate to High \\
\hline & Bergersen et al. (2003) & $15 / 20$ & Moderate to High \\
\hline & Chow et al. (2012) & $15 / 20$ & Moderate to High \\
\hline & Chow et al. (2018) & $16 / 20$ & High \\
\hline & Currier et al. (2003) & $13 / 20$ & Moderate to High \\
\hline & De Socio et al. (2007) & $12 / 20$ & Moderate to High \\
\hline & Durand et al. (2011) & $15 / 20$ & Moderate to High \\
\hline & Gazzaruso et al. (2014) & $11 / 20$ & Moderate to High \\
\hline & Jerico et al. (2005) & $14 / 20$ & Moderate to High \\
\hline & Kakinami et al. (2013) & $14 / 20$ & Moderate to High \\
\hline & Senoner et al. (2019) & $14 / 20$ & Moderate to High \\
\hline & Sico et al. (2015) & $13 / 20$ & Moderate to High \\
\hline & Triant et al. (2007) & $14 / 20$ & Moderate to High \\
\hline \multirow{6}{*}{$\begin{array}{l}\text { Bone Mineral Density } \\
(n=6)\end{array}$} & Arnsten et al. (2007) & $14 / 20$ & Moderate to High \\
\hline & Bruera et al. (2003) & $9 / 20$ & Low to Moderate \\
\hline & Loiseau-Peres et al. (2002) & $7 / 20$ & Low to Moderate \\
\hline & Slama et al. (2017) & $15 / 20$ & Moderate to High \\
\hline & Tebas et al. (2000) & $11 / 20$ & Moderate to High \\
\hline & Teichmann et al. (2003) & $12 / 20$ & Moderate to High \\
\hline \multirow[t]{6}{*}{ Cancer $(n=6)$} & Bower et al. (2003) & $10 / 20$ & Moderate to High \\
\hline & Crum-Cianflone et al. (2010) & $12 / 20$ & Moderate to High \\
\hline & Meijde et al. (2017) & $13 / 20$ & Moderate to High \\
\hline & Massad et al. (2016) & $13 / 20$ & Moderate to High \\
\hline & Palefsky et al. (1998) & $13 / 20$ & Moderate to High \\
\hline & Hammad et al. (2011) & $15 / 20$ & Moderate to High \\
\hline \multirow[t]{5}{*}{ Diabetes $(n=5)$} & Brown et al. (2005) & $16 / 20$ & High \\
\hline & Butt et al. (2009) & $13 / 20$ & Moderate to High \\
\hline & Justman et al. (2003) & $13 / 20$ & Moderate to High \\
\hline & Rasmussen et al. (2012) & $12 / 20$ & Moderate to High \\
\hline & Tien et al. (2007) & $14 / 20$ & Moderate to High \\
\hline \multirow{4}{*}{$\begin{array}{l}\text { Respiratory/Pulmonary } \\
\text { disease }(n=4)\end{array}$} & Crothers et al. (2011) & $16 / 20$ & High \\
\hline & Crothers et al. (2006) & $15 / 20$ & Moderate to High \\
\hline & Gingo et al. (2013) & $15 / 20$ & Moderate to High \\
\hline & Patil et al. (2014) & $14 / 20$ & Moderate to High \\
\hline \multirow{4}{*}{$\begin{array}{l}\text { Neurocognitive dysfunction } \\
(n=4)\end{array}$} & Ciccarelli et al. (2011) & $15 / 20$ & Moderate to High \\
\hline & Ciccarelli et al. (2012) & $14 / 20$ & Moderate to High \\
\hline & Crum-Cianflone et al. (2013) & $16 / 20$ & High \\
\hline & Giesbrecht et al. (2014) & $15 / 20$ & Moderate to High \\
\hline
\end{tabular}




\begin{tabular}{|c|c|c|c|}
\hline $\begin{array}{l}\text { Comorbidityl } \\
\text { Health Challenge }\end{array}$ & Author & $\begin{array}{l}\text { AXIS } \\
\text { Criteria Met }\end{array}$ & Quality Rating \\
\hline \multirow{3}{*}{$\begin{array}{l}\text { Altered body fat } \\
\text { distribution }(n=3)\end{array}$} & Carr et al. (1998) & $10 / 20$ & Moderate to High \\
\hline & Bacchetti et al. (2005) & $18 / 20$ & High \\
\hline & Grant et al. (2016) & $16 / 20$ & High \\
\hline \multirow{2}{*}{$\begin{array}{l}\text { Vestibular and auditory } \\
\text { dysfunction }(n=2)\end{array}$} & Cohen et al. (2012) & $15 / 20$ & Moderate to High \\
\hline & Torre et al. (2013) & $13 / 20$ & Moderate to High \\
\hline Neurological conditions $(n=1)$ & Mateen et al. (2012) & $14 / 20$ & Moderate to High \\
\hline $\begin{array}{l}\text { Sexual function/desire } \\
(n=1)\end{array}$ & Dijkstra et al. (2018) & $19 / 20$ & High \\
\hline $\begin{array}{l}\text { Metabolic syndrome } \\
(n=1)\end{array}$ & Bonfanti et al. (2007) & $13 / 20$ & Moderate to High \\
\hline Renal system dysfunction $(n=1)$ & Lucas et al. (2007) & $14 / 20$ & Moderate to High \\
\hline $\begin{array}{l}\text { Age associated co-morbidities } \\
(n=1)\end{array}$ & Schouten et al. (2014) & $15 / 20$ & Moderate to High \\
\hline $\begin{array}{l}\text { Gastrointestinal conditions } \\
(n=1)\end{array}$ & Siddiqui et al. (2007) & $15 / 20$ & Moderate to High \\
\hline
\end{tabular}

osteoporosis or osteopaenia in PLHIV [30-35]. Four articles rated as moderate to high quality [30,33-35]. Of note two further articles rated low to moderate quality (AXIS score 5-10), rendering them the two lowest rated articles in this review [31,32].

The earliest study, compared three groups of men, HIV+ve on protease inhibitors (HIV+ve $+\mathrm{PI})$, HIV+ve not on PIs (HIV+ve -PI), and HIV-ve controls [34]. BMD was calculated from three proximal femoral measurement regions, showing that osteopenia and osteoporosis incidence in $\mathrm{HIV}+\mathrm{ve}+\mathrm{PI}$ men was significantly greater than controls, and concluding that osteoporosis was a side effect of PIs [36]. This was later supported by others who also showed significantly reduced BMD in the lumbar spine as well as the femur [30-32]. A 38\% increased fracture rate in PLHIV, was also reported, but this was not significant compared with HIV-ve controls [30]. In white HIV+ve males, both HIV and use of ART were shown to adversely affect bone metabolism and increase osteoporosis rates, particularly at HIV seroconversion when key bone formation biomarkers decreased, leading to reduced sclerostin [33]. Evidence supporting a reduced BMD specific to women living with HIV was provided by only one article in this review, showing osteoporosis rates of $14 \%$, and osteopenia identified by significantly greater loss of $B M D$ in the lumbar spine compared to matched HIV-ve women $(p=0.01)$ [35].

\section{HIV and Cancer}

All six articles in this category, rated as moderate to high quality. Increased prevalence $(23 \%)$ for human papillomavirus (HPV) infection as a potential cancer precursor in HIV+ve women [36], and an increased 4 -year incidence $(49 \%)$ and risk of high-grade squamous intra-epithelial lesions (HSIL) as a potential precursor to anal cancer in HIV+ve men [37] was identified. Increased incidence rates for lung cancer [38], anal cancer [39,40], AIDS and non-AIDS defining cancers [41] were reported in four further articles.

Anal cancer incidence rates per 1000,000 person-years were substantially greater in both the pre- and postART era compared to the HIV-ve population (32 and 56 respectively vs. 1.4) [39]. When the pre- and post-ART era were compared, incidence was increased during in the latter, especially at a younger age [39], but overall survival rate did not differ between PLHIV and the HIVve population $(p=0.49)$ [40]. One article reported the incidence of lung cancer, reporting that HIV related lung cancer in the post-ART era occurred more frequently, but these authors did not report whether statistical significance was achieved [38].

However, lung cancer was identified as the most common non-AIDS defining cancer (NADC) in PLHIV with higher incidence rates than HIV-ve controls, along with Hodgkin Lymphoma ( $\mathrm{SIR}=4.2 ; 95 \% \mathrm{Cl}: 2.8-6.5$, and $\mathrm{SIR}=16.1 ; 95 \%$ $\mathrm{Cl}$ : 5.0-51.3 respectively) [41]. Further, the incidence of all types of AIDS defining and NADCs was shown to be significantly increased in PLHIV (SIR=3.8; 95\% Cl: 3.34.4), with twice the risk of developing a NADC [41].

HIV and Diabetes Mellitus (DM)

There were five articles in this category, one rated high quality [42], and four moderate to high [43-46]. One 
article reported prevalence of DM [43], two incidence in women $[44,46]$, one both prevalence and incidence [44], and one risk [45]. Studies of HIV+ve women showed no overall significant difference in incident DM in women with no ART exposure (HIV+ve -ART) compared to HIVve controls $[44,46]$. Nevertheless, those exposed to ART including PIs ( $\mathrm{HIV}+\mathrm{ve}+\mathrm{PI})$, showed significantly increased DM incidence compared to HIV-ve women, and women on ART including reverse transcriptase inhibitors (RTI) [44]. Furthermore, longer cumulative exposure to ART including nucleoside reverse transcriptase inhibitors (NRTI) also significantly increased DM incidence [46].

This review identified that HIV+ve men exposed to ART had greater incidence $(10 \%)$ of DM compared to HIV-ve men (3\%) [42]. Similarly, a later study in a mostly male population, concluded that HIV itself did not increase DM risk but long-term use of ART did [43]. More specifically, Rasmussen, reported that between 1996 and 1999 PLHIV had a significantly greater risk for DM compared to HIV-ve controls, but not so between 1999 and 2010, concluding that some ART no longer in use may have increased DM risk [45].

\section{HIV and Respiratory/Pulmonary Disease}

Four articles reported on respiratory related comorbidities and health challenges [49-50]. One rated as high [48], and three moderate to high quality $[47,49,50]$. Significantly lower prevalence of sleep disordered breathing (SDB) in HIV+ve men compared to HIV-ve individuals was reported in one of these studies [50]. In another study, COPD and bacterial pneumonia were the most common pulmonary disease amongst PLHIV, and albeit asthma, incidences of COPD, lung cancer, pulmonary hypertension, pulmonary fibrosis, and lung infections in HIV+ve veterans and younger individuals were greater than in HIV-ve controls [48]. PLHIV on ART and with lower HIV Ribonucleic acid levels, were less likely to have COPD, asthma or pulmonary infections [48]. These findings align with statistically increased incidence of COPD reported in men in the preART era compared with HIV-ve individuals, and incidence of respiratory infections in men and women in both preand post-ART eras [49]. This supports earlier reports of greater COPD prevalence, and a $50-60 \%$ greater risk of developing COPD in PLHIV [47].

\section{HIV and Neurocognitive Dysfunction}

The four studies included in this category, rated high [51], and moderate to high [52-54]. Three reported prevalence [51,52,54], and one risk [54].

The earliest article found that HIV+ve men demonstrated significantly greater prevalence of HIV-associated neurocognitive disorders (HAND) in three specific neuropsychological test domains, concluding that the drug efavirenz was associated with increased risk of cognitive impairment [52]. In a similar population, significantly more overall neuropsychological performance deficit was also reported [53].

Contrary findings were later found in a predominantly male population $\mathbf{( 9 5 . 5 \% )}$ of military beneficiaries. Prevalence of neurocognitive impairment between HIV+ve and HIV-ve beneficiaries was not significantly different, and neither was there any significant difference between PLHIV for $>10$ years compared to those recently infected [51].

Cognitive function impairment was reported in a female population, with information processing speed, executive function, and quality of decision making significantly affected compared to HIV-ve controls [54].

\section{HIV and Body Composition}

Three eligible studies reported on body composition changes. Two rated as high quality $[55,56]$, and one moderate to high [57]. The earliest study reported that only PLHIV on ART+PI had significantly lower total body fat mass compared to HIV-ve controls, and after an average 13.9 months on PI therapy, significant lipoatrophy in all body regions albeit the abdomen was noted [57]. This was supported by a later study which found that significant fat loss occurred in the peripheries of face, upper and lower limbs and buttocks [55]. However, these authors also reported a loss of central body fat. The third article in this category reported similar findings, but specifically results showed that within 96 weeks of ART initiation, lean body mass and fat increased in PLHIV compared to HIV-ve controls, although after 96 weeks fat increases remained significantly higher, but lean mass significantly reduced [56].

\section{HIV and Vestibular or Auditory Dysfunction}

Two articles of moderate to high quality were included in this review $[58,59]$. Vestibular impairments measured by the head thrust, Romberg and Dix-Hallpike manoeuvre, and balance were not significantly greater in community dwelling men and women with HIV [58], and no evidence of cochlear dysfunction was found in HIV+ve men and women regardless of ART exposure [59].

HIV and Neurological Conditions Sexual Function/Desire Metabolic Syndrome Renal System Dysfunction Age Associated Co-morbidities (AANC) or astrointestinal conditions

Several comorbidities or health challenges were reported by only one eligible article. One study was of high 
methodological quality [60], others rated moderate to high [61-65]. For each comorbidity or health challenge, significantly greater prevalence $[60,61,64,65]$, or incidence $[62,63]$ was reported in PLHIV compared with HIV-ve controls.

Incidence of end stage and chronic renal disease in African-American PLHIV was more than 10 times that of matched HIV-ve controls [62]. PLHIV had higher incidence of nervous system infections, dementia, peripheral nervous system disorders, and seizures/epilepsy, but not stroke [63]. There was greater prevalence of metabolic syndrome [61], diarrhoea [65], 'AANC' hypertension, MI, and PAD [64], but significantly lower erectile function, desire, and satisfaction [60].

\section{Discussion}

This systematic review critically appraised 51 studies conducted in developed countries, and which reported health challenges and co-morbidities experienced by PLHIV compared to matched HIV-ve individuals. To the authors knowledge no previous review has summated and appraised literature to identify if any health challenges and comorbidities are experienced by, or pose a greater risk in PLHIV than HIV-ve individuals.

An array of comorbidities and health challenges were identified in studies, which were of moderate to high quality, albeit two [31,32]. Thus, findings reliably represent PLHIV in developed countries. Sample size justification, addressing and categorising non-responders were the main methodological concerns particularly in the low to moderate quality articles, which potentially introduced volunteer bias, reducing reliability of some study findings. Notwithstanding, this review identified substantial evidence that higher prevalence, incidence, or risk for several comorbidities and health challenges exist in PLHIV in developed countries, even after statistical adjustment for known risk factors. Further, results suggest that the prevalence, incidence, and risk of developing certain comorbidities and health challenges relate to current or historical exposure to ART regimes.

\section{HIV and Cardio Vascular (CV) Related Disease}

Evidence specific to PAD, ischaemic stroke, AMI, mortality from CV disease overall, and coronary atherosclerosis indicated that rates of certain CV comorbidities surmount those in matched HIV-ve individuals. This has been attributed to an increasing burden of vascular risk factors combined with the ageing HIV population [66]. Additionally, PLHIV may have an increased risk of ischemic stroke if they are not virally suppressed $[16,22,25]$, which reflects the results from other non- comparative studies $[66,69]$. In contrast, increased prevalence of hypertension in PLHIV compared to HIV-ve controls was not found by this review.

There were three articles which reported risk of CV disease [27-29]. All used the FRS which has shown accuracy to measure risk in PLHIV [68]. Greater risk for CV disease was unsubstantiated by two of the studies $[28,29]$. Albeit conducted in populations across different countries (Italy, Norway and USA) these studies had similar population demographics, recruitment sites, moderate to high study quality, and were published within nine years of each other. Therefore, the divergent results demonstrated by Bergeson et al. [27] cannot be easily explained, complicating the ability to draw firm conclusions on overall CV disease risk from the current review.

$\mathrm{CV}$ disease was the largest category of evidence in this review, but most comorbidities and health challenges were represented by less than four articles. Thus, the body of comparative evidence is limited, and any inferences made should be placed in context of this. Future comparative research on CV disease is required.

\section{HIV and Changes in Bone Mineral Density (BMD)}

A link between HIV infection, and low BMD was indicated by this review, despite two studies having low to moderate methodological quality. Slama et al. [33], postulated that dysregulation of bone turnover markers increased levels of bone reabsorption as a precursor to osteopaenia in PLHIV, refuting evidence that dysregulation in bone turnover markers, and low BMD are not evident in young PLHIV [69].

$B M D$ was measured using Dual Energy $X$-ray Absorptiometry (DEXA) in five out of six studies, thus allowing comparison [30-32,34,35]. These studies included males and females, decreasing confounding factors such as risk for osteoporosis in older females [70].

Regardless, of the roll that dysregulate bone turnover markers may have on BMD, in PLHIV there was moderate to strong evidence of reduced BMD in this review, indicating that health professionals should screen for decreased BMD in the management of PLHIV.

\section{HIV and Cancer}

There was moderate to strong evidence that prevalence, incidence and risk of certain cancers, and precursors to cancer development, such as HPV infection and HSIL is greater in PLHIV than HIV-ve individuals. The rates of lung [38], and anal cancer [39], ADC and NADC [41] remain higher in PLHIV despite advances in ART, and frequency of SCCA has increased in younger PLHIV 
[40]. These findings cannot be a sole consequence of increased life expectancy and reduced opportunistic infections. Thus, early detection of cancer red flags is a primary responsibility for health professionals [71], and the importance of understanding the link between HIV infection and cancer via professional educational programs, is crucial.

\section{HIV and Diabetes Mellitus (DM)}

There was minimal and conflicting evidence of increased prevalence of DM in this review [42,43]. Butt et al. [43], who reported lower prevalence in PLHIV, had a large veteran population $(n=3,227)$, confirmed $D M$ via ICD-9 codes, and recorded medication. In contrast, Brown et al. [42], reported higher prevalence in a younger MSM population ( $n=568)$, using self-reported DM diagnosis and medications. This study's smaller sample population, and self-reporting methods may have led to erroneous rates of $D M$, and thus contradictory findings.

Two studies indicated greater incidence of DM relate to ART with PI and RTI exposure [44], or with cumulative NRTI use [46], and between 1999-2010 another noted decreased DM risk prior to ART exposure [45]. This supports a narrative review of DM in PLHIV that found associations with NRTI, PI and specific ART regimes [72].

Evidence from this systematic review identified that DM incidence and risk are increased in PLHIV who are exposed to ART. Specific details of which ART may increase incidence and risk remain unclear. Future research is recommended to determine the specific ART regimes that increase DM risk, and assess how increased risk may be minimised.

\section{HIV and Respiratory/Pulmonary Disease}

Increased prevalence, incidence or risk of COPD [47], and lung infections, but not asthma $[48,49]$ was evidenced by this review when adjusted for confounding factors such as smoking. Studies had large sample populations, and used valid diagnostic methods, allowing comparability. Two studies $[47,48]$ had a mostly male and veteran population with a mean age 15 years older than that of the later study of MSM and women [49], but population differences did not cause divergent findings.

COPD incidence was greater in the pre-ART era (19841994), and only in MSM, not females [49]. The incidence of several other non-infectious respiratory conditions appeared to be no greater in the post-ART era [49], and may represent the direct effect of ART, and the under representation of females in pre-ART era studies due to either decreased reporting, or fewer HIV+ve female numbers [73].
A single study reported lower rates of SDB in PLHIV [50], and had a much smaller population than other studies in this review. Demonstrating, insufficient evidence for SDB as a major health problem in PLHIV. This review indicates that COPD and respiratory infections remain concerning in PLHIV, but due to the limited number of studies identified it remains unclear whether other non-infectious respiratory conditions pose significant heath challenges in PLHIV over and above the HIV-ve population. Regular and optimal health promotion with specific focus on COPD and respiratory infections is recommended, and would ensure appropriate treatment to improve health care for PLHIV.

\section{HIV and Neurocognitive Dysfunction}

This review suggests PLHIV experience NC dysfunction $[51,52,54]$. However, evidence was limited, with only one study on a female population [54], and one study finding no significant increased prevalence [51], despite all having similar sample size, outcome measures and percentage of ART exposure. Until further comparative research on NC function is available, no conclusions can be reached regarding the impact of living with HIV on cognitive ability compared to HIV-ve individuals.

\section{HIV and Altered Body Fat Distribution}

Evidence was limited, but lipoatrophy in most peripheral regions was identified [55-57]. Carr et al. [57], hypothesised ART causes insulin resistance and mitochondrial toxicity resulting in these body changes, and in all studies the majority of PLHIV were taking ART. Evidence suggests that gains in lean mass and total body fat resulting from 'return to health' is not maintained after 96 weeks of ART exposure, negating any initial gained benefits in body composition [56]. Such body composition changes have subsequently been documented in previous studies [74]. This review identified historical and convergent evidence that negative effects of ART on body fat persist, despite improvement in HIV drug management. This may have considerable influence on the health of PLHIV.

\section{HIV and Other Co-morbidities and Health Challenges} In this review only one or two articles reported on each of several different comorbidities and health challenges [58-65]. De Jong et al. [75] proposed synaptic loss, local inflammation and degeneration followed by cochlear damage and central pathology in PLHIV, but in this review, there was no indication that cochlear function and vestibular impairments are greater in PLHIV with or without ART than HIV-ve controls. Further, the paucity of comparative studies on this topic, aligns with previous comment that literature is limited [76]. 
A similar paucity of literature was evident for several other comorbidities and health challenges. Despite this, existing studies provide insight that certain conditions such as nervous system infection, dementia, metabolic syndrome, peripheral nervous system disorders, sexual dysfunction and desire, renal disorders, AANCs, and diarrhoea may be experienced with greater frequency in PLHIV compared to HIV-ve individuals. Although, previous reviews have reported high rates of some of these conditions in PLHIV, they made no direct comparison with HIV-ve individuals [77-81]. Thus, evidence on these co-morbidities in PLHIV remains limited, with further research needed.

\section{Strengths and limitations of this Systematic Review}

All articles in this review included HIV-ve controls, allowing comparison of prevalence, incidence, and risk for comorbidities and health challenges with PLHIV. A valid quality appraisal tool was utilised, and two reviewers conducted article appraisal under blinded conditions which increased standardisation and reduced selection bias.

This review was limited by the inclusion of articles not published in English, and studies conducted in developing countries. Therefore, literature pertaining to some health challenges and co-morbidities may have been excluded. However, demographics, access to ART, and health care in developing countries often differs from developed countries. To have included studies from developing countries would have introduced confounding factors, and rendered the conclusions and recommendations of this review less specific. Understanding the comorbidities and health conditions of PLHIV in developing countries is important, and should be the subject of a future review.

\section{Relevance to Health Care Professionals}

A number of health challenges and comorbidities should be a focus of concern when attending PLHIV. Any increased rate and risk over and above healthy uninfected individuals pose a unique burden on PLHIV, with potential to increase disability and reduce quality of life. This review provides evidence that should be taken into consideration by health professionals treating PLHIV, to ensure routine screening and early onward referral, appropriate diagnosis and management, to improve outcomes.

\section{Conclusions}

Moderate to high quality evidence indicates increased rates or risk of ischaemic stroke, myocardial infarction, reduced bone mineral density, lung and anal cancer, chronic obstructive pulmonary disease, lung infections, and peripheral lipodystrophy in PLHIV compared with
HIV-ve individuals in developed countries. However, evidence for other comorbidities remains limited or inconclusive. Future comparative primary research is needed to build on current evidence and provide a larger body of evidence to increase understanding on how HIV and the role of ART affects the co-morbidities and health challenges which have greater impact on the health and wellbeing of PLHIV.

\section{List of abbreviations}

AIDS: Acquired immunodeficiency syndrome

AMI: Acute myocardial infarction

ART: Antiretroviral therapy

AXIS: Appraisal Tool for Cross Sectional Studies

BMD: Bone mineral density

COPD: Chronic obstructive pulmonary disease

CVD: Cardiovascular Disease

DEXA: Dual Energy X-ray Absorptiometry

DM: Diabetes mellitus

FRS: Framingham risk score

HIV: Human Immunodeficiency Virus

HIV+ve: HIV positive

HIV-ve: HIV negative

HPV: Human papillomavirus

NRTI: Non-reverse transcriptase inhibitors

PAD: Peripheral artery disease

PI: Protease inhibitor

PLHIV: People living with HIV

PROSPERO: Prospective Register of Systematic Reviews

RTI: Reverse transcriptase inhibitors

SDB: Sleep disordered breathing

\section{References}

1. O'Brien KK, Bayoumi AM, Strike C, Young NL, Davis AM. Exploring disability from the perspective of adults living with HIV/AIDS: Development of a conceptual framework. Health Qual Life Outcomes, 2008;6(1):76.

2. Cheung CC, Ding E, Sereda P, Yip B, Lourenco L, Barrios $\mathrm{R}$, et al. Reductions in all-cause and causespecific mortality among HIV-infected individuals receiving antiretroviral therapy in British Columbia, Canada: 2001-2012. HIV Med, 2016;17(9):694-701.

3. Cheung KT, Fairley CK, Read TRH, Denham I, Fehler G, Bradshaw CS, et al. HIV Incidence and Predictors of Incident HIV among Men Who Have Sex with Men Attending a Sexual Health Clinic in Melbourne, Australia. PLoS One, 2016; 11(5).

4. Nakagawa F, May M, Phillips A. Life expectancy living with HIV. Curr Opin Infect Dis, 2013;26(1):17-25.

5. Erlandson KM, Schrack JA, Jankowski CM, Brown TT, Campbell TB. Functional Impairment, Disability, and 
Frailty in Adults Aging with HIV-Infection. Curr HIV/ AIDS Reports, 2014;11(3):279-290.

6. Samji H, Cescon A, Hogg RS, Modur SP, Althoff KN, Buchacz K. et al. Closing the Gap: Increases in Life Expectancy among Treated HIV-Positive Individuals in the United States and Canada. PLoS One, 2013. 8(12).

7. Grijsen ML, Vrouenraets $S M$, Steingrover R, Lips $P$, Reiss $\mathrm{P}$, Wit FW, et al. High prevalence of reduced bone mineral density in primary HIV-1-infected men. AIDS, 2010;24(14):2233-2238.

8. Brown J, Roy A, Harris R, Filson S, Johnson M, Abubakar I, et al. Respiratory symptoms in people living with HIV and the effect of antiretroviral therapy: A systematic review and meta-analysis. Thorax, 2017;72(4):355-366.

9. Erlandson KM, Fiorillo S, Masawi F, Scherzinger A, McComsey GA, Lake JE, et al. Antiretroviral initiation is associated with increased skeletal muscle area and fat content. AIDS, 2017;31(13):1831-1838.

10. Gobbens, R.J., Luijkx, K.G., Wijnen-Sponselee, M.T., and Schols, J.M.,Toward a conceptual definition of frail community dwelling older people. Nurs. Outlook, 2010. 58(2):76-86.

11. Moher D, Liberati A, Tetzlaff J, Altman DG. Preferred reporting items for systematic reviews and meta-analyses: The PRISMA statement. BMJ, 2009;339:b2535.

12. Huang Y, Wu Y, Schwebel DC, Zhou L, Hu G. Disparities in under-five child injury mortality between developing and developed countries: 1990-2013. Int. J. Environ. Res. Public. Health, 2016;13(7):653.

13. Downes MJ, Brennan ML, Williams HC, Dean RS. Development of a critical appraisal tool to assess the quality of cross-sectional studies (AXIS). BMJ Open, 2016;6(12):e011458.

14. Bull C, Byrnes J, Hettiarachchi R, Downes M. A systematic review of the validity and reliability of patient-reported experience measures. Health Ser. Res., 2019;54(5):1023-1035.

15. Beckman JA, Duncan MS, Alcorn CW, So-Armah K, Butt AA, Goetz MB, et al. Association of human immunodeficiency virus infection and risk of peripheral artery disease. Circulation, 2018;138(3):255-265.

16. Chow FC, Regan S, Zanni MV, Looby SE, Bushnell CD, Meigs $\mathrm{JB}$, et al. Elevated ischemic stroke risk among women living with HIV infection. AIDS, 2018;32(1):59-67.

17. Baekken M, Os I, Sandvik L, Oektedalen O. Hypertension in an urban HIV-positive population compared with the general population: Influence of combination antiretroviral therapy. J. Hypertens, 2008;26(11):2126-2133.

18. Bergersen BM, Sandvik L, Dunlop O, Birkeland $\mathrm{K}$, Bruun JN. Prevalence of hypertension in HIV- positive patients on highly active retroviral therapy (HAART) compared with HAART-naïve and HIVnegative controls: results from a Norwegian study of 721 patients. Eur J Clin Microbiol Infect Dis, 2003;22(12):731-736.

19. Gazzaruso C, Bruno R, Garzaniti A, Giordanetti S, Fratino $P$, Sacchi $P$, et al. Hypertension among HIV patients: prevalence and relationships to insulin resistance and metabolic syndrome. J Hypertens, 2003;21(7):1377-1382.

20. Jericó C, Knobel H, Montero M, Sorli ML, Guelar A, Gimeno JL, et al. Hypertension in HIV-infected patients: prevalence and related factors. $A m \mathrm{~J}$ hypertens, 2005;18(11):1396-1401.

21. Senoner T, Barbieri F, Adukauskaite A, Sarcletti M, Plank F, Beyer C, et al. Coronary atherosclerosis characteristics in HIV-infected patients on long-term antiretroviraltherapy: insightsfromcoronarycomputed tomography-angiography. AIDS, 2019;33(12):18531862.

22. Chow F, Regan S, Feske S, Meigs J, Grinspoon S, Triant V. Comparison of ischemic stroke incidence in HIV-infected and non-HIV-infected patients in a US Health Care System. J Acquir Immune Defic Syndr, 2012;60:351-358.

23. Currier JS, Taylor A, Boyd F, Dezii CM, Kawabata $\mathrm{H}$, Burtcel $\mathrm{B}$, et al. Coronary heart disease in HIVinfected individuals. J Acquir Immune Defic Syndr, 2003;33(4):506-512.

24. Durand M, Sheehy O, Baril JG, Lelorier J, Tremblay $\mathrm{CL}$. Association between HIV infection, antiretroviral therapy, and risk of acute myocardial infarction: a cohort and nested case-control study using Québec's public health insurance database. J Acquir Immune Defic Syndr, 2011;57(3):245-253.

25. Sico JJ, Chang C-CH, So-Armah K, Justice AC, Hylek $E$, Skanderson $M$, et al. HIV status and the risk of ischemic stroke among men. Neurology, 2015;84(19):1933-1940.

26. Triant VA, Lee H, Hadigan C, Grinspoon SK. Increased acute myocardial infarction rates and cardiovascular risk factors among patients with human immunodeficiency virus disease. J Clin Endocrinol Metab, 2007;92(7):2506-2512.

27. Bergersen BM, Sandvik L, Bruun JN, Tonstad S. Elevated Framingham risk score in HIV-positive patients on highly active antiretroviral therapy: results from a Norwegian study of 721 subjects. Eur J Clin Microbiol Infect Dis, 2004;23(8):625-630.

28. De Socio GV, Martinelli L, Morosi S, Fiorio M, Roscini AR, Stagni G, et al. Is estimated cardiovascular risk higher in HIV-infected patients than in the general population? Scand J Infect Dis, 2007;39(9):805-812. 
29. Kakinami L, Block RC, Adams MJ, Cohn SE, Maliakkal B, Fisher SG. Risk of cardiovascular disease in HIV, hepatitis C, or HIV/hepatitis C patients compared to the general population. Int J Clin, 2013;67(1):6-13.

30. Arnsten JH, Freeman R, Howard AA, Floris-Moore M, Lo $\mathrm{Y}$, Klein RS. Decreased bone mineral density and increased fracture risk in aging men with or at risk for HIV infection. AIDS, 2007;21(5):617-623.

31. Bruera D, Luna N, David DO, Bergoglio LM, Zamudio J. Decreased bone mineral density in HIV-infected patients is independent of antiretroviral therapy. AIDS, 2003;17(13):1917-1923.

32. Loiseau-Pérès $S$, Delaunay $C$, Poupon $S$, Lespessailles $\mathrm{E}$, Ballouche N, Arsac P, et al. Osteopenia in patients infected by the human immunodeficiency virus. A case control study. Joint bone spine, 2002;69(5): 482-485.

33. Slama L, Reddy S, Phair J, Palella FJ, Jr., Brown TT. Changes in bone turnover markers with HIV seroconversion and ART initiation. J Antimicrob, 2017; 72(5):1456-1461.

34. TebasP, PowderlyWG, ClaxtonS, MarinD, TantisiriwatW, Teitelbaum SL, et al. Accelerated bone mineral loss in HIV-infected patients receiving potent antiretroviral therapy. AIDS, 2000;14(4):F63-67.

35. Teichmann J, Stephan E, Lange U, Discher T, Friese G, Lohmeyer J, et al. Osteopenia in HIV-infected women prior to highly active antiretroviral therapy. $J$ Infect, 2003;46(4):221-227.

36. Massad L, Keller M, Xie X, Minkoff H, Palefsky J, DaSouza $G$, et al. Multitype infections with human papillomavirus: Impact of human immunodeficiency virus coinfection. Sex. Transm. Dis, 2016;43(10):637641.

37. Palefsky JM, Holly EA, Ralston ML, Jay N, Berry JM, Darragh TM. High incidence of anal high-grade squamous intra-epithelial lesions among HIV-positive and HIV-negative homosexual and bisexual men. AIDS, 1998;12(5):495-503.

38. Bower M, Powles T, Nelson M, Shah P, Cox S, Mandelia $S$, et al. HIV-related lung cancer in the era of highly active antiretroviral therapy. AIDS, 17(3):371-375.

39. Crum-Cianflone NF, Hullsiek KH, Marconi VC, Ganesan A, Weintrob A, Barthel RV, et al. Anal cancers among HIV-infected persons: HAART is not slowing rising incidence. AIDS, 2010;24(4):535-543.

40. Hammad N, Heilbrun LK, Gupta S, Tageja N, Philip PA, Shields AF, et al. Squamous cell cancer of the anal canal in HIV-infected patients receiving highly active antiretroviral therapy: a single institution experience. Am J Clin Oncol, 2011;34(2):135-139.

41. Meijide H, Pértega S, Rodríguez-Osorio I, CastroIglesias Á, Baliñas J, Rodríguez-Martínez G, et al.
Increased incidence of cancer observed in HIV/ hepatitis C virus-coinfected patients versus HIVmonoinfected. AIDS, 2017;31(8):1099-1107.

42. Brown TT, Cole SR, Li X, Kingsley LA, Palella FJ, Riddler SA, et al. Antiretroviral therapy and the prevalence and incidence of diabetes mellitus in the multicenter AIDS cohort study. Arch Intern Med, 2005;165(10):1179-1184.

43. Butt AA, McGinnis K, Rodriguez-Barradas MC, Crystal $S$, Simberkoff $M$, Goetz $M B$, et al. HIV infection and the risk of diabetes mellitus. AIDS, 2009; 23(10):1227-1234.

44. Justman JE, Benning L, Danoff A, Minkoff H, Levine A, Greenblatt RM, et al. Protease inhibitor use and the incidence of diabetes mellitus in a large cohort of HIV-infected women. J Acquir Immune Defic Syndr, 2003;32(3):298-302.

45. Rasmussen L, Mathiesen E, Kronborg G, Pedersen C, Gerstoft J, Obel N. Risk of diabetes mellitus in persons with and without HIV: A danish nationwide population-based cohort study. Plos ONE, 2012;7.

46. Tien PC, Schneider MF, Cole SR, Levine AM, Cohen $M$, DeHovitz J, et al. Antiretroviral therapy exposure and incidence of diabetes mellitus in the Women's Interagency HIV Study. AIDS, 2007;21(13):1739-1745.

47. Crothers K, Butt AA, Gibert CL, Rodriguez-Barradas MC, Crystal S, Justice AC. Increased COPD among HIV-positive compared to HIV-negative veterans. Chest, 2006;130(5):1326-1333.

48. Crothers K, Huang L, Goulet JL, Goetz MB, Brown ST, Rodriguez-Barradas MC, et al. HIV infection and risk for incident pulmonary diseases in the combination antiretroviral therapy era. Am J Respir Crit Care Med, 2011;183(3):388-395.

49. Gingo MR, Balasubramani GK, Kingsley L, Rinaldo CR, Jr., Alden CB, Detels R, et al. The impact of HAART on the respiratory complications of HIV infection: longitudinal trends in the MACS and WIHS cohorts. PLOS ONE, 2013;8(3):e58812.

50. Patil SP, Brown TT, Jacobson LP, Margolick JB, Laffan A, Johnson-Hill L, et al. Sleep disordered breathing, fatigue, and sleepiness in HIV-infected and -uninfected men. PLoS One, 2014;9(7):e99258.

51. Crum-Cianflone NF, Moore DJ, Letendre $S$, Roediger MP, Eberly L, Weintrob A, et al. Low prevalence of neurocognitive impairment in early diagnosed and managed HIV-infected persons. Neurology, 2013; 80(4):371-379.

52. Ciccarelli N, Fabbiani M, Di Giambenedetto S, Fanti I, Baldonero $\mathrm{E}$, Bracciale $\mathrm{L}$, et al. Efavirenz associated with cognitive disorders in otherwise asymptomatic HIV-infected patients. Neurology, 2011;76(16):14031409. 
53. Ciccarelli N, Fabbiani M, Baldonero E, Fanti I, Cauda $R$, Giambenedetto SD, et al. Effect of aging and human immunodeficiency virus infection on cognitive abilities. J Am Geriatr Soc, 2012;60(11):2048-2055.

54. Giesbrecht CJ, Thornton AE, Hall-Patch C, Maan EJ, Cote HCF, Money DM, et al. Select neurocognitive impairment in HIV-infected women: Associations with HIV viral load, hepatitis C virus, and depression, but not leukocyte telomere length. PLOS ONE, 2014;9(3).

55. Bacchetti P, Gripshover B, Grunfeld C, Heymsfield S, McCreath $\mathrm{H}$, Osmond $\mathrm{D}$, et al. Fat distribution in men with HIV infection. J Acquir Immune Defic Syndr. 2005;40(2):121-131.

56. Grant PM, Kitch D, McComsey GA, Collier AC, Bartali $B$, Koletar SL, et al. Long-term body composition changes in antiretroviral-treated HIV-infected individuals. AIDS, 2016;30(18):2805-2813.

57 Carr A, Samaras K, Burton S, Law M, Freund J, Chisholm DJ, et al. A syndrome of peripheral lipodystrophy, hyperlipidaemia and insulin resistance in patients receiving HIV protease inhibitors. AIDS, 1998;12(7):F51-58.

58. Cohen HS, Cox C, Springer G, Hoffman HJ, Young MA, Margolick JB, et al. Prevalence of abnormalities in vestibular function and balance among HIVseropositive and HIV-seronegative women and men. PLOS ONE, 2012;7(5).

59. Torre P, 3rd, Hoffman HJ, Springer G, Cox C, Young $M$, Margolick JB, et al. Cochlear function among HIVseropositive and HIV-seronegative men and women. Ear Hear, 2014;35(1):56-62.

60. Dijkstra M, Van Lunsen RHW, Kooij KW, Davidovich U, Van Zoest RA, Wit FWMN, et al. HIV-1 status is independently associated with decreased erectile function among middle-aged MSM in the era of combination antiretroviral therapy. AIDS, 2018;32(9):1137-1146.

61. Bonfanti P, Giannattasio C, Ricci E, Facchetti R, Rosella E, Franzetti $M$, et al. HIV and metabolic syndrome: a comparison with the general population. $J$ Acquir Immune Defic Syndr, 2007;45(4):426-431.

62. Lucas GM, Mehta SH, Atta MG, Kirk GD, Galai N, Vlahov $D$, et al. End-stage renal disease and chronic kidney disease in a cohort of African-American HIV-infected and at-risk HIV-seronegative participants followed between 1988 and 2004. AIDS, 2007;21(18):24352443.

63. Mateen FJ, Shinohara RT, Carone M, Miller EN, McArthur JC, Jacobson LP, et al. Neurologic disorders incidence in HIV+ vs HIV- men: Multicenter AIDS Cohort Study, 1996-2011. Neurology, 2012;79(18):18731880.
64. Schouten J, Wit FW, Stolte IG, Kootstra NA, van der Valk M, Geerlings SE, et al. Cross-sectional comparison of the prevalence of age-associated comorbidities and their risk factors between HIV-infected and uninfected individuals: the AGEhIV cohort study. Clin Infect Dis, 2014;59(12):1787-1797.

65. Siddiqui U, Bini EJ, Chandarana K, Leong J, Ramsetty $\mathrm{S}$, Schiliro D, et al. Prevalence and impact of diarrhea on health-related quality of life in HIV-infected patients in the era of highly active antiretroviral therapy. J Clin Gastroenterol, 2007;41(5):484-490.

66. Benjamin LA, Bryer A, Emsley HCA, Khoo S, Solomon T, Connor MD. HIV infection and stroke: current perspectives and future directions. Lancet NNeurol, 2012;11(10):878-890.

67. Silva-Pinto A, Costa A, Serrão R, Sarmento A, Abreu P. Ischaemic stroke in HIV-infected patients: a casecontrol study. HIV Med, 2017;18(3):214-219.

68. Thompson-Paul AM, Lichtenstein KA, Armon C, Palella FJ, Skarbinski J, Chmiel JS, et al. Cardiovascular disease risk prediction in the HIV outpatient study. Clin Infect Dis, 2016;63(11):1508-1516.

69. Mora S, Puzzovio M, Giacomet V, Fabiano V, Maruca K, Capelli S, et al. Sclerostin and DKK-1: two important regulators of bone metabolism in HIV-infected youths. Endocrine, 2015;49(3):783-790.

70. Tella SH, Gallagher JC. Prevention and treatment of postmenopausal osteoporosis. J Steroid Biochem Mol Biol, 2014;142:155-170.

71. Cabry F, Graham C, Jeffrey S, Hellawell $M$. Documentation of spinal red flags during physiotherapy assessment. Br J Health Care Manag, 2017; 23:574-580.

72. Paik IJ, Kotler DP. The prevalence and pathogenesis of diabetes mellitus in treated HIV-infection. Best Pract. Res. Clin. Endocrinol. Metab, 2011;25(3):469-478.

73. Centers for Disease Control and Prevention. HIV Surveillance Report, 2008; vol. 20. http://www. cdc.gov/hiv/topics/surveillance/resources/ reports/. Published June 2010. Accessed January 20, 2021.

74. Alves MD, Brites C, Sprinz E. HIV-associated lipodystrophy: a review from a Brazilian perspective. Ther Clin Risk Manag, 2014;10:559.

75. de Jong MA, Luder A, Gross M. Main aspects of peripheral and central hearing system involvement in unexplained HIV-related hearing complaints. Front neurol, 2019;10:845.

76. Heinze B, Swanepoel DW, Hofmeyr LM. Systematic review of vestibular disorders related to human immunodeficiency virus and acquired immunodeficiency syndrome. J Laryngol Otol, 2011;125(9):881-890. 
77. Chirca N, Streinu-Cercel A, Jinga V, Streinu-Cercel A. Erectile dysfunction in a cohort of HIV-infected male patients. BMC infectious diseases, 2014;14(S7).

78. Fine DM, Perazella MA, Lucas GM, Atta MG. Renal disease in patients with HIV infection: Epidemiology, pathogenesis and management. AIDS Int, 2008;68(7): 963-980.

79. Fumaz CR, Ayestaran A, Perez-Alvarez N, Muñoz-Moreno JA, Ferrer MJ, Negredo E, et al. Clinical and emotional factors related to erectile dysfunction in HIV-infected men. Am J Men's Health, 2017;11(3):647-653.

80. Logan C, Beadsworth MBJ, Beeching NJ. HIV and diarrhoea: what is new? Curr. Opin. Inf. Dis, 2016;29(5):486-494.

81. Pérez I, Moreno T, Navarro F, Santos J, Palacios R. Prevalence and factors associated with erectile dysfunction in a cohort of HIV-infected patients. Int J STD AIDS, 2013;24(9):712-715. 